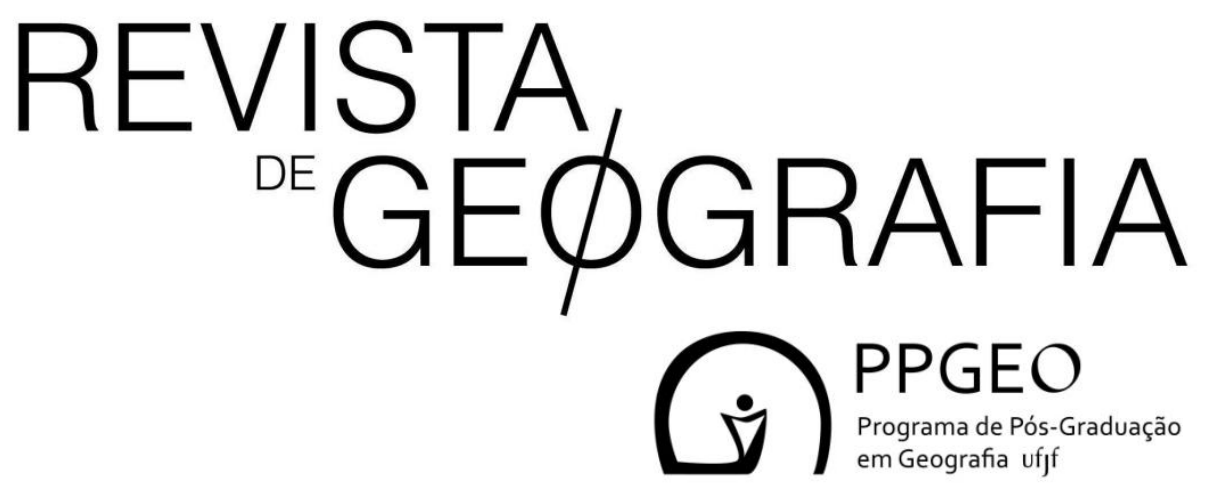

\title{
ESTADO DA ARTE DAS PESQUISAS EM PROTEÇÃO E RECUPERAÇÃO DE NASCENTES PARA O CONSUMO HUMANO EM PROPRIEDADES RURAIS NO BRASIL
}

\author{
STATE OF THE ART OF RESEARCHES IN PROTECTION AND RECOVERY OF WATER \\ SPRINGS FOR HUMAN CONSUMPTION IN RURAL PROPERTIES IN BRAZIL
}

Msc. Tiago Vinicius Silva Athaydes Universidade Estadual de Maringá - UEM, Doutorando em Geografia Av. Colombo, 5.790 - Jd. Universitário - Maringá-PR, CEP: 87020-900

E-mail: tiagooathaydes@gmail.com

Dr Mauro Parolin

Universidade Estadual de Maringá - UEM,

Professor no Programa de Pós-Graduação em Geografia Av. Colombo, 5.790 - Jd. Universitário - Maringá-PR, CEP: 87020-900

E-mail: mauroparolin@gmail.com

Dr Jefferson de Queiroz Crispim Universidade Estadual do Paraná - UNESPAR - Campus de Campo Mourão, Professor no curso de Geografia Licenciatura e Bacharelado Av. Comendador Norberto Marcondes, 733 - Centro - Campo Mourão-PR, CEP: 87.303-100 


\title{
Resumo
}

O Brasil tem avançado na questão da temática sobre melhoria da qualidade da água no meio rural. Em destaque, temos a Política Federal para Pagamentos de Serviços Ambientais n 14.119/2021. A pesquisa objetivou indicar o estado da arte das produções cientificas no Brasil para a proteção e recuperação de nascentes no meio rural. Realizaram-se buscas de publicações nas Plataformas Google Acadêmico e nos Periódicos da CAPES. As palavras chave foram: proteção e recuperação de nascentes; análise da qualidade da água e área rural. Quantificaram-se os assuntos tratados em cada produção: Educação Ambiental (EA), Práticas de Preservação e Recuperação da Vegetação (PRV), Técnicas Implementadas (TI) e Monitoramento/Analises da Qualidade da água (QA). 64,5\% das publicações apresentaram mais de um critério. Realizou-se o mapeamento e 0 ano das publicações e foram demonstradas as áreas de conhecimento dos autores. Os resultados indicaram que PRV foi retratado em 63 publicações, EA em 55, TI em 43 e QA em 30. A Região Sul se destacou com 35 publicações, seguida da Região Sudeste com 30, Nordeste com 15, Centro Oeste com 9 e Norte com 1. As áreas de conhecimento predominante dos autores são Biologia com 28 artigos, seguida de Geografia com 20 e Agronomia com 18. Os anos com maiores publicações foram 2014 e 2017 com onze publicações cada. Contabilizou-se 78 produções realizadas por pesquisadores filiados a universidades e institutos públicos e 12 por pesquisadores filiados a instituições particulares. As publicações se mostram desiguais nas regiões brasileiras, especialmente na região norte.

Palavras-Chaves: Quantificação de publicação cientifica; Saneamento ambiental; Melhoria da qualidade da água.

\begin{abstract}
Brazil has advanced on the issue of improving water quality in rural areas. In particular, we have the Federal Policy for Payments for Environmental Services $n^{\circ} 14.119$ / 2021. The research aimed to indicate the state of the art of scientific productions in Brazil for the protection and recovery of springs in rural areas. There were publications in Google Scholar search platforms and CAPES Journal. The key words were: protection and recovery of springs; analysis of water quality and rural area. The subjects treated in each production were quantified: Environmental Education (EA), Practices of Preservation and Recovery of Vegetation (PRV), Implemented Techniques (IT) and Monitoring / Analysis of water quality (QA). $64.5 \%$ of the publications presented more than one criterion. The mapping and year of publications were carried out and the authors' areas of knowledge were demonstrated. The results indicated that PRV was portrayed in 63 publications, EA in 55, TI in 43 and QA in 30 . The South Region stood out with 35 publications, followed by the Southeast Region with 30, Northeast with 15, Midwest with 9 and North with 1. The authors' predominant knowledge areas are Biology with 28 articles, followed by Geography with 20 and Agronomy with 18. The years with the largest publications were 2014 and 2017 with eleven publications each. There were 78 productions made by researchers affiliated with universities and public institutes and 12 by researchers affiliated with private institutions. The publications are unequal in the Brazilian regions, especially in the northern region.
\end{abstract}

Keywords: Quantification of scientific publication; Environmental sanitation; Improvement of water quality.

ISSN: 2236-837X

V. 11, n. 1, 2021
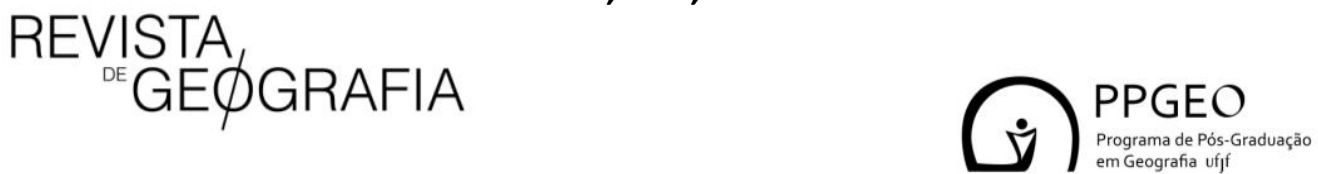


\section{INTRODUÇÃO}

O desenvolvimento de ações de proteção e preservação ambiental vem sendo tema ascendente na atualidade. Podemos destacar que, em nível global, a preocupação mais efetiva com o meio ambiente se deu a partir da realização da Conferência das Nações Unidas sobre o Meio Ambiente Humano ou Conferência de Estocolmo em 1972 e posteriormente, com a Conferência Rio-92, realizada no Rio de Janeiro.

No Brasil, as ações para a preservação e proteção do meio ambiente são expressas com: a) criação do Código Florestal em 1965; b) Política Nacional do Meio Ambiente em 1981; c) Política Nacional de Educação Ambiental em 1997; d) Política Nacional de Recursos Hídricos em 1997; e) Plano Nacional de Recursos Hídricos em 2006; f) Política Nacional de Saneamento Básico em 2007; g) Plano Nacional de Saneamento Básico em 2013; h) a reformulação do novo Código Florestal em 2012; i) Programa Saneamento Brasil Rural em 2019; e j) Pagamentos por Serviços Ambientais em 2021. Construíram-se, dessa maneira, normas para o uso dos recursos naturais de forma mais racional.

Dentre as políticas públicas nacionais supracitadas, em especial, para assuntos relacionados ao saneamento básico no meio rural, neste caso, para ações para a melhoria da qualidade e abastecimento da água, observam-se avanços, mas que ainda necessitam alcançar a universalização.

Diante do exposto, a presente pesquisa teve por objetivo a quantificação da produção científica sobre a proteção e recuperação de nascentes localizadas em propriedades rurais cuja água tem por finalidade o consumo humano. Para tanto, estabeleceram-se como temas prioritários para as áreas rurais questões como: preservação ambiental em áreas de nascentes, saneamento básico, educação ambiental e técnicas utilizadas.

Como será observada, a produção científica sobre o tema é relativamente abundante. No entanto, de forma inédita, o trabalho estabelece uma quantificação aliada ao mapeamento da produção científica no Brasil.

Além desse fato, traz em seu bojo informações sobre as instituições que trabalham ou trabalharam com o tema e a quantificação sobre a área de formação dos pesquisadores envolvidos.

ISSN: 2236-837X

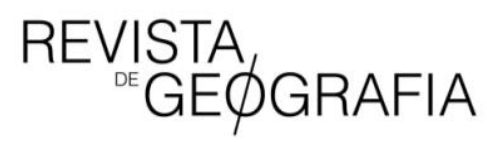

V. 11, n. 1, 2021

${ }^{D E}$ GE $\phi$ GRAFIA

(1) PPGEO 
Nesse sentido, o trabalho indica lacunas de conhecimento em determinadas regiões do Brasil, bem como áreas onde devem ser investidos recursos para a melhoria das condições ambientais e consequentemente da qualidade de vida.

\title{
2. MATERIAL E MÉTODOS
}

A pesquisa operou buscas de material produzido sobre nascentes no Portal de Periódicos da CAPES e Google Scholar. As palavras-chave selecionadas foram: proteção e recuperação de nascentes; análise da qualidade da água; e área rural.

A definição de Estado da Arte descreve como sendo toda produção científica realizada por meio de teses, dissertações, artigos em revistas e em eventos.

As pesquisas referentes ao Estado da Arte visam mapear onde as produções estão acontecendo em um determinado território. Exposto desta forma por Ferreira:

\begin{abstract}
Definidas como de caráter bibliográfico, elas parecem trazer em comum o desafio de mapear e de discutir uma certa produção acadêmica em diferentes campos do conhecimento, tentando responder que aspectos e dimensões vêm sendo destacados e privilegiados em diferentes épocas e lugares, de que formas e em que condições têm sido produzidas certas dissertações de mestrado, teses de doutorado, publicações em periódicos e comunicações em anais de congressos e de seminários (FERREIRA, 2002, p. 258).
\end{abstract}

A busca pelo Estado da Arte sobre o tema proposto visa identificar como está sendo abordado nas diversas produções e também ajuda a determinar quais áreas, instituições e pesquisadores estão envolvidos.

Para a escolha das produções, foram considerados os critérios que atendiam a Educação Ambiental (EA), práticas de preservação e recuperação da vegetação (PRV), técnicas implementadas ( $\mathrm{Tl}$ ), como exemplo, de sistemas de proteção por Solo-Cimento e Caxambu e cercamento no raio de cinquenta metros $(50 \mathrm{~m})$ do afloramento da nascente que devem estar protegidas com vegetação conforme o Código Florestal (12.651/2012) e o monitoramento e análises da qualidade da água (QA). Várias produções atenderam mais de um critério (64,5\%), como por exemplo, a discussão sobre EA e PRV em áreas de nascentes, sendo computados, desta forma, mais de um critério para estas produções.

As produções selecionadas encontram-se como artigos em eventos e revistas, trabalhos de conclusão de curso em graduação e pós-graduação lato sensu, dissertações de mestrado e teses de doutorado.

ISSN: 2236-837X

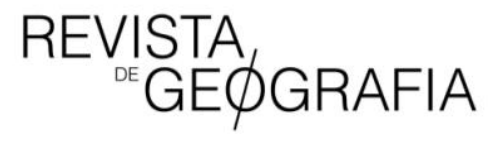

V. 11, n. 1, 2021 
Detalhou-se os pesquisadores, áreas de formação, o ano das publicações e as instituições de ensino e entidades ligadas às questões ambientais e agrárias, por meio de busca dos nomes dos autores na plataforma Lattes.

Consistiu-se em separar e mapear as produções por regiões para detalhar 0 enquadramento de cada produção segundo os critérios estabelecidos.

\section{RESULTADOS E DISCUSSÃO}

As nascentes são afloramentos da água subterrânea para a superfície (PINTO et al., 2012). A partir destes afloramentos, as nascentes acabam por contribuir com o abastecimento de rios, lagos, riachos e na captação e abastecimento humano, como acontece nas propriedades rurais.

Diante desse fato, cumpre-se protegê-las. "As áreas no entorno das nascentes e dos olhos d'água perenes, qualquer que seja sua situação topográfica, no raio mínimo de 50 (cinquenta) metros devem ser protegidas por áreas de preservação permanente" (CÓDIGO FLORESTAL BRASILEIRO, 2012, p. 6).

A proteção no entorno da nascente é de extrema importância para o equilíbrio hídrico do volume e da qualidade da água e para evitar processos de assoreamento nas áreas de afloramento das nascentes. Sendo assim, as matas ciliares (vegetação ripária) servem como uma barreira natural de proteção. "Quando chove, a mata ciliar também impede que uma quantidade muito grande de água caia de uma vez só no rio, e assim evita enchentes" (DEMICHEI, 2011, p. $15)$.

Outras ações para a proteção e recuperação das nascentes podem ser realizadas dentro ou próximo aos locais de afloramento, e.g. técnica de Solo-Cimento e Caxambu. Esses modelos são utilizados para a complementação da proteção com vegetação.

São utilizados principalmente no meio rural, onde os agricultores realizam o consumo da água no dia a dia.

É mais comum a verificação de ações de proteção e recuperação de nascentes serem realizadas por órgãos ambientais, universidades e cooperativas rurais.

No entanto, não se podem descartar ações cuja gênese parta dos próprios proprietários dos estabelecimentos.

ISSN: 2236-837X

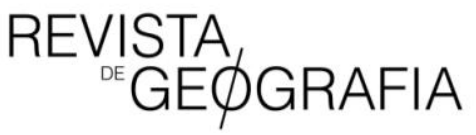

V. 11, n. 1, 2021

${ }^{\mathrm{DE}} \mathrm{GE}$ QGRAFIA

(1) PPGEO

Programa de Pós-Graduação 
No Estado do Paraná, entidades como EMATER (Instituto Paranaense de Assistência Técnica e Extensão Rural), SEMA (Secretária do Meio Ambiente e Recursos Hídricos) e IAT (Instituto Água e Terra) - antigo IAP (Instituto Ambiental do Paraná), têm desenvolvido projetos para a melhoria da qualidade da água em zonas rurais, em especial para a proteção e recuperação de nascentes, com a técnica de Solo-Cimento.

O solo-cimento é uma tecnologia barata, de simples aplicação e já vem sendo divulgada a mais de três décadas no Paraná. É um material alternativo e de baixo custo utilizam solo argiloso, cimento e água. A massa permite que o trabalho seja realizado dentro da água pelo próprio trabalhador rural, não necessitando mão de obra especializada (SEMA, 2010, p. 15).

O sistema Caxambu diferencia-se da técnica de Solo-Cimento. Nesse sistema, é alocada dentro da nascente uma tubulação de concreto na localidade em que é encontrado o olho d'água.

Trata-se de um tubo de concreto de $20 \mathrm{~cm}$ de diâmetro, contendo quatro saídas, duas constituídas de dois tubos de PVC de $25 \mathrm{~mm}$, (ou mais, conforme a necessidade) por $30 \mathrm{~cm}$ de comprimento, que serão as duas saídas da água e, outras duas formadas por dois tubos de PVC de $40 \mathrm{~mm} \times 30 \mathrm{~cm}$ de comprimento, um tubo para limpeza da estrutura e outro para "ladrão" (CALHEIROS et al., 2004, p. 41).

As legislações e as técnicas criadas provocaram um avanço significativo na tentativa de reduzir impactos ao meio ambiente.

Partindo da Revolução Industrial, passando pelas décadas de 1960, 1970, 1980 e chegando ao final dos anos 1990 com uma série de acordos, convenções e leis, que surgiram com a finalidade de tornar o desenvolvimento econômico menos impactante ao meio ambiente e à própria humanidade (POTT e ESTRELA, 2017, p. 271).

Contudo, o meio rural ainda carece de atenção e de melhorias, sobretudo para o saneamento básico.

A busca pela garantia da qualidade de vida e da preservação do meio ambiente nas zonas rurais deve atender essas preocupações para o saneamento, com projetos que atendam à qualidade da água e também de ações para o despejo correto do esgoto doméstico.

À vista desta questão, o Saneamento Ambiental tem grande importância, ocasionando a preservação da água potável de qualidade para o consumo humano e também para o equilíbrio ambiental.

A contaminação da água por falta de saneamento básico ocasiona poluição de rios e lagos, principalmente aquelas oriundas da falta de coleta e tratamento do esgoto doméstico, bem como das atividades industriais.

ISSN: 2236-837X

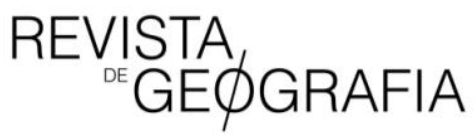

V. 11, n. 1, 2021 
O ato de consumir água contaminada é um agravante para a saúde dos seres humanos, como também para outros seres vivos. Por conseguinte, a falta de ações e práticas de saneamento básico pode gerar um agravo para a saúde pública de um determinado município, estado ou até mesmo de um país.

Um exemplo de ação para contornar esse problema é o da FUNASA (Fundação Nacional da Saúde) a qual tem desenvolvido programas para a melhoria da qualidade de vida em zonas rurais e que é o órgão principal que trata dos assuntos sobre saneamento básico nas áreas rurais. Desses programas refere ao projeto de universalização do acesso à água no semiárido.

O governo decidiu incluir no Plano Brasil Sem Miséria, um programa de universalização do acesso à água para consumo humano no semiárido, onde serão investidos nos próximos dois anos mais de R\$ 220 milhões. "Água é alimento: é com base nesse conceito que os técnicos da Funasa trabalham para assegurar o abastecimento da população rural com água de boa qualidade", afirma o diretor do Departamento de Saúde Ambiental, Henrique Pires (FUNASA, 2011, p. 9).

Não se pode esquecer que o processo de recuperação e preservação de nascentes passa necessariamente pela educação ambiental, pois ela é um dos mecanismos que auxiliam na manutenção e motivação de tais atividades.

A educação ambiental aliada aos projetos e técnicas desenvolvidas para a preservação e recuperação de nascentes torna-se forte aliada do Poder Público no retorno do investimento empreendido.

Para situar as produções cientificas no Brasil sobre o tema, objetivou-se em organizar em tabela as seguintes informações: Instituições envolvidas e se a mesma é pública ou privada; Número de autores envolvidos em cada produção; área de formação dos pesquisadores; local da pesquisa e o tema que envolve a pesquisa. As informações organizadas visaram dar suporte para o georrefenciamento das produções separadas por regiões: Sul, Sudeste, Centro-Oeste, Nordeste e Norte. Verificou-se a existência de noventa (90) produções científicas sobre nascentes (Tabela 1). 
TABELA 1: Resultado do levantamento realizado, indicando as Publicações (Pub.), Instituições envolvidas, natureza jurídica (pública ou privada), área de formação, local da pesquisa e temas (Educação Ambiental (EA), Preservação/Reflorestamento da Vegetação (PRV), Tecnologias

PUB.

INSTITUIÇÕES

ENVOLVIDAS

UFRGRS/RS

UNESPAR/PR

UNIBAVI/SC

UNESPAR/PR

UFMS E CPAN/MS

UTFPR/PR

UTFPR /PR

UNIASELVI

UNESPAR/PR

UNIOESTE/PR

EMBRAPA/PR

UNESPAR/PR

UTFPR/PR

UFSM e EMATER/RS

$\begin{array}{cc}\text { UFSM/RS } & \mathrm{x} \\ \text { UFRGS/RS } & \mathrm{x} \\ \text { UFRGS/RS } & \mathrm{x} \\ \text { UFRGS/RS } & \mathrm{x} \\ \text { UNIOESTE /PR } & \mathrm{x} \\ \text { FAG/PR } & \\ \text { UFSC/SC } & \mathrm{x} \\ \text { UFSM/RS } & \mathrm{x} \\ \text { IFPR/PR } & \mathrm{X}\end{array}$

PÚB
$\mathbf{0}$
$\mathbf{X}$
$\mathbf{X}$

$\mathbf{X}$
$\mathbf{X}$
$\mathbf{X}$
$\mathbf{X}$
$\mathbf{X}$
$\mathbf{X}$
$\mathbf{X}$
$\mathbf{X}$
$\mathbf{X}$
$\mathbf{X}$

$x$

$\mathbf{X}$

$\mathbf{X}$

$\mathbf{x}$

Implementadas (TI) e Monitoramento/Análises da Qualidade da Água (QA)

$\begin{array}{cc} \\ \mathbf{O} & \text { PRIVAD } \\ \mathbf{X} & \mathbf{0} \\ \mathrm{X} & \\ & \mathrm{X}\end{array}$

AREA DE FORMAÇÃO

LOCAL DA PESQUISA

TEMAS

\section{Geografia (2).}

Geografia (3).

$X \quad$ Eng. Ambiental (1); Biologia (3);

Eng. Civil (1).

Geografia (2).

Contábeis (5)

Eng. Ambiental (1); Agronomia (1). Geografia (1); Psicologia (1)

$X$

$\mathbf{X}$

$\mathbf{x}$

Eng. Florestal (2); Agronomia; Tecnologia em ADM (1).

Agronomia (1); Geografia (3). Agronomia (2).

Eng. Química (1); Eng. Florestal e Formação de Professores para a Educação Profissional e

Tecnológica (1); Tecnologia em Agricultura Familiar (1).

Biologia (1); Eng. Química (1). Geografia (1).

Tecno. em Planejamento e Gestão para o desenvolvimento Rural (1).

Tecno. em Desenvolvimento Rural. ADM (1).

$\mathbf{X}$

Agronomia (2).

Eng. Florestal (1); Eng. Sanitária

$$
\text { (3). }
$$

Eng. Florestal (1).

\section{Rolante/RS}

Campo Mourão/PR

Lauro Muller/SC

Campina da Lagoa/PR

Apucarana/PR

Marmeleiro/PR

Candói/PR

Ipíra e Piratuba/SC

Iretama/PR

Guaraniaçu /PR

Machadinho /RS

Tec. Agroecologia (2); Gestão Ambiental (2); Biologia (1).
Mato Rico/PR

Itapejara d'Oeste/PR

Dona Francisca/RS

Tenente Portela/RS

$$
\text { Rolante/RS }
$$

Bom Progresso/RS

Três Passos/RS

Francisco Beltrão/PR

Corbélia/PR

Lages/SC

Itaara/RS

Assis Chateaubriand

/PR
EA; PRV.

EA; PRV; TI; QA.

EA; PRV.

EA; PRV; TI; QA.

EA.

EA; TI.

EA.

EA; PRV; TI.

EA; PRV; TI.

EA; TI.

PRV.

EA; TI; QA.

EA; TI; QA.

EA; PRV; TI.

EA; PRV.

PRV.

PRV.

EA.

EA; PRV; TI.

QA.

EA; TI; QA.

PRV.

PRV; TI. 


\section{UNIOESTE/ PR}

UNIOESTE/ PR

UTFPR/PR

UNISC/RS

\section{UTFPR/PR}

UFSC/SC

UFPR/PR

UFPR/PR

UNIVALI/SC

UnC/SC

UFSM/RS

INIJUÍ/RS

UFLA/MG

UFU/MG

UFRJ/RJ

Universidade de Itaúna/MG Prefeitura de Barra

Mansa/RJ

UFES/ES

\section{Faculdade Redentor/RJ}

\section{UFU/MG}

\section{EMATER e IFF/RJ}

Universidade Cândido

$$
\text { Mendes/RJ }
$$

IF Sul de Minas/MG

$\mathbf{x}$

$\mathbf{x}$

$\mathrm{X}$

$x$

$\mathrm{x}$
Tec. Ambiental (2); Eng. Civil; Zootecnia (1).

Geografia (1).

Eng. Ambiental (1).

$\mathbf{X}$

Eng. Civil (1); Eng. Ambiental (1); Agronomia (1).

Agronomia (1)

Eng. Sanitária-Ambiental (1).

Biologia (1).
Ciências (1).
Geografia (1).

Farmácia (2).

$\mathbf{X}$

Tecno. em Agricultura Familiar e Sustentabilidade (1). Sociologia (1).

Eng. Florestal (2); Antropologia; Agronomia (1); Economia (1). Geografia (2).

Gestão Ambiental (1); Química e Eng. Química (1); Economia (1);

Eng. Florestal (1). Biologia (4).

Gestão Ambiental; Geografia (2).

Eng. Florestal; Eng. Agrícola;

Agronomia (2); Biologia (2); Eng.

$$
\text { Alimentos. }
$$

$$
\text { Biologia (4). }
$$

Eng. Ambiental (1); Geografia e Direito (1); Geografia (1).

Agronomia (1); Eng. Agrimensura;

Eng. Eletrônica (1).

$x$
Palotina/PR

Francisco Beltrão/PR

Caçador/SC

Vera Cruz/RS

Mariópolis/PR

Lages, Campo Belo do Sul e Cerro

Negro/SC

Iretama/PR

Palmital/PR

Camboriú/SC

Taió/SC

Dona Francisca/RS

\section{Horizontina/RS}

Medina/MG

Araguari/MG

Barra Mansa/RJ

Itauna/MG

Barra Mansa/RJ

Alegre/ES

Varre-Sai/RJ

Uberlândia/MG

Macaé/RJ

Barra Mansa/RJ

Inconfidentes/MG
PRV.

PRV; TI; QA;

TI.

PRV; TI.

EA; PRV; TI; QA.

\section{EA; PRV; TI. \\ EA; PRV.}

EA; TI; QA.

QA.

EA; PRV; TI; QA.

EA; PRV.

EA; PRV.

EA; PRV; TI. EA; QA.

\section{EA; PRV.} PRV.

QA.

QA.

EA; PRV; TI.

EA; PRV; TI.

EA; PRV; TI.

PRV; QA. 


\section{IFCE/CE}

Prefeitura Municipal de São José dos Campos/SP UNIFEI e Prefeitura Municipal Santa Rita do Sapucaí/MG UFOP/MG

Prefeitura Municipal de Juiz de Fora/MG

UFVJM/MG

UNIFEI/MG

IFMG/MG

UTFPR/PR

UNESP/SP

IF Sul de Minas/MG

\section{UFLA/MG \\ UNIFOR/MG UFES/ES \\ UFES/ES \\ IFCE/CE \\ UFG/GO}

Coop. de Agricultura

Familiar de Itapuranga/GO Unievangélica /GO UFMG/MG
Veterinária (1).
Economia (1); Antropologia (1).

Gestão Ambiental (1); Eng. Química

e Formação de Docentes (1)

$$
\text { Biologia (1). }
$$$$
\text { Biologia (3) }
$$

História e Geografia (1); Biologia (1).

$$
\text { ADM (1). }
$$

Eng. Florestal (1).

Ciências Sociais e Gestão Ambiental

(1); Informática e Téc. em

Agroecologia (1); Agronomia e Biologia (1).

Serviço Social (1); ADM (1); Ciências Sociais (1).

Turismo e Eng. Ambiental (3); Biologia (1); Eng. Civil (1).

Tec. Meio Ambiente (2); Biologia (1). Gestão Ambiental (1).

Eng. Ambiental (1).

Téc em Meio Ambiente (5); Ciências

Agrárias (1); Enfermagem (1); Biologia (1).

$$
\text { Pedagogia (1). }
$$

Eng. Ambiental-Sanitária (1). Eng Florestal (1).

Eng Florestal (1).

Zootecnia e Eng. Ambiental (1). Geografia (5)
Turmalina, Veredinha, Medina, Joaíma, Monte Formoso e Jequitinhonha/MG Barra Mansa/RJ

\section{Bebedouro/SP} Serro/MG

São José dos Campos/SP

Santa Rita do Sapucaí/MG

Ouro Branco/MG

Juiz de Fora/MG

Veredinha e Turmalina/MG

$$
\text { Itabira/MG }
$$

Dom Cavati/MG

São Miguel Arcanjo/SP

Machado/SP

Muzambinho

$$
\text { /MG }
$$

\section{Coimbra/MG}

Formiga/MG

Alegre/ES

Guaçuí e São José do Calçado/ES

Rio Verde/GO

Jataí e Perolandia/GO

Itapuranga/GO

Anápolis/GO
EA.

EA; PRV; TI; QA.

EA; PRV; QA. PRV.

EA.

PRV; TI.

PRV; QA.

PRV.

PRV.

PRV; TI.

QA.

EA; PRV.

TI.

QA.

EA; PRV; TI.

PRV; TI; QA.

QA.

QA. EA; PRV.

EA.

PRV.
EA; PRV; TI; QA. 


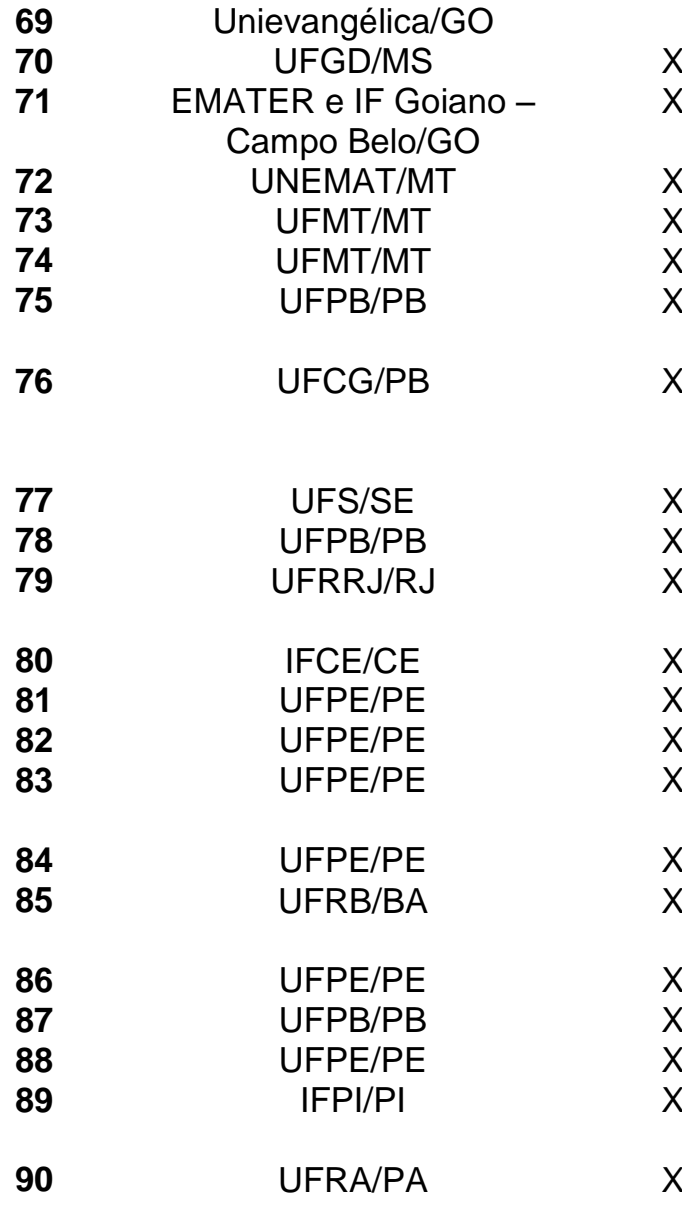

e Eng. Eletrônica da Computação e Eng. Civil (1); Ed. Física e ADM (1);

Pedagogia (1); Geografia (1); Biologia (1).

X
Direito e Contábeis (1); Biologia (1). Direito (1).

Agronomia (1).

Biologia (1); História (1). Biologia (1).

Eng. Agrícola-Ambiental (1). ADM (3); Eng. Civil (1); Eng. Agrícola (1).

Eng. Agrícola (1); Eng. Florestal (1); Ciências Sociais (1); Agronomia (1); Eng. Produção (1).

Biologia (1); Eng. Florestal (1). Eng. Florestal (1). Agronomia (1).

\section{Biologia (1).}

Agronomia (1).

Gestão Ambiental e Geografia (1). Biologia (1).

Biologia (1).

Biologia (1); Geografia (1); Agronomia (1); Eng. Florestal (1).

Biologia (2); Geografia (1).

Geografia (1).

Biologia (1)

Tecnologia em Gestão Ambiental (1); Geologia (1).

Agronomia (5); Matemática e Pedagogia (1).

\section{Ouro Verde/GO}

Caarapó/MS

Monte Alegre de Goiás/GO

Reserva do Cabaçal/MT

$$
\text { Cáceres/MT }
$$

São José do Povo/MT

Pedras de Fogo/PB

Gurinhém/PB

Areia Branca/SE

Pedras de Fogo/PB

Planalto, Barra do Choça e Vitória da Conquista/BA

Cabo do Santo Agostinho/PE

Pombos e Vitória de Santo Antão/PE Vitória de Santo Antão/PE

Brejinho, Iguaraci, Carnaíba, Itapetim, Quixaba/PE

Vitória de Santo Antão/PE

Cruz das Almas/BA

Vitória de Santo Antão e Moreno/PE João Pessoa e Conde/PB

Vitória de Santo Antão /PE Pedro II/PI

Irutuia/PA
PRV; TI.

EA; PRV. PRV; TI.

EA.

EA; PRV; TI.

EA; PRV; TI.

EA.

EA; PRV.

PRV. PRV; TI.

EA; PRV; TI; QA

EA; PRV; TI.

EA; PRV; TI; QA

EA; PRV; TI; QA.

PRV.

EA; PRV; TI; QA. PRV; QA.

EA; PRV.

EA; PRV; TI.

EA; PRV; TI; QA. PRV; TI.

EA.

Fonte: Autores (2020). 
Foram encontradas trinta e cinco (35) publicações na região Sul (Figura 1A) e vinte e nove (29) publicações na região Sudeste (Figura 1B).

FIGURA 1: Publicações científicas sobre proteção e recuperação de nascentes em área rural: 1A) Região Sul; 1B) Região Sudeste

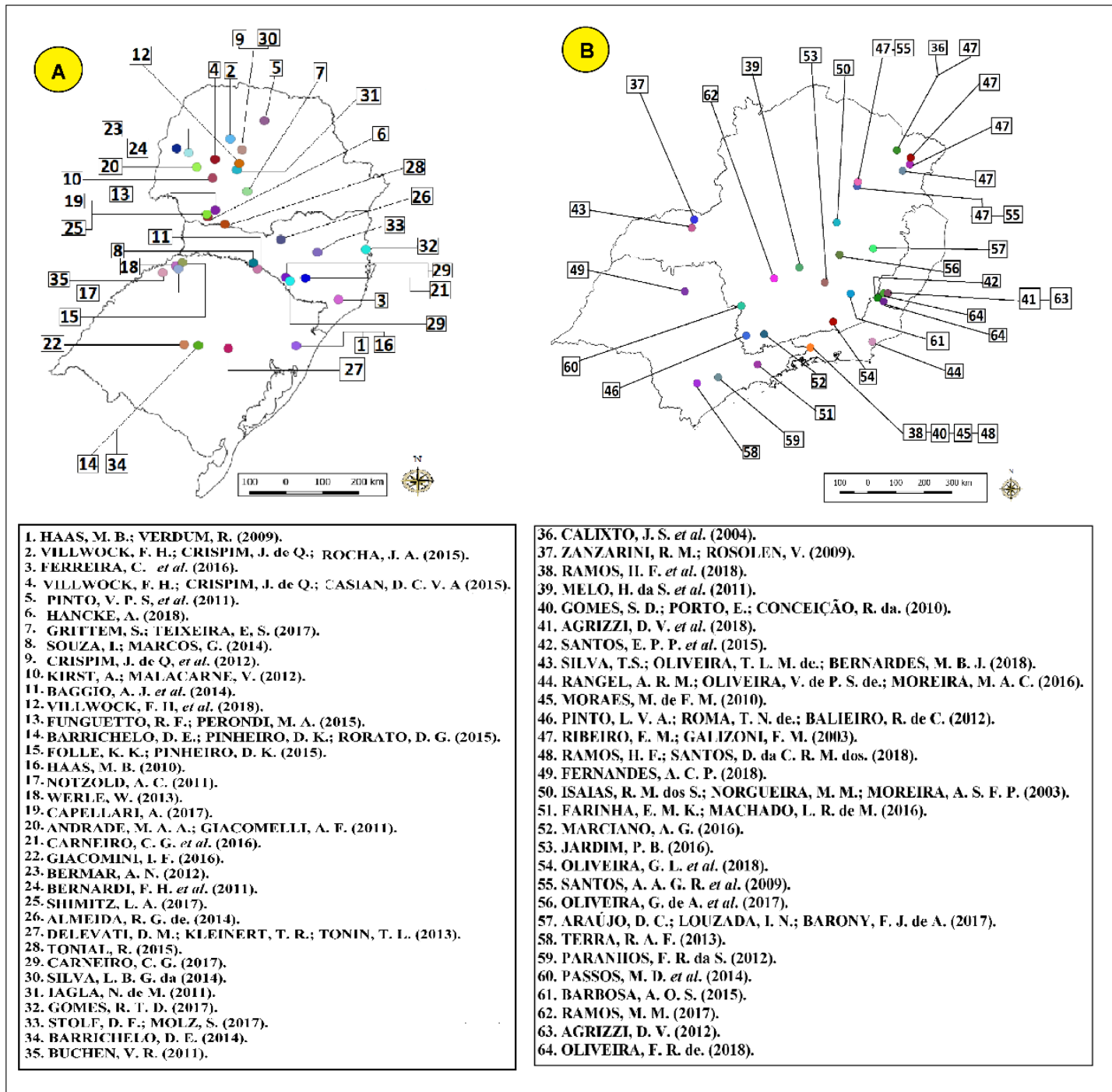

Fonte: Autores (2020).

$\mathrm{Na}$ região Centro-Oeste o tema de maior ocorrência foi sobre PRV com oito (8) publicações e o de menor foi sobre QA, com uma (1) (Figura 2A).

A região Nordeste também apresentou maior ocorrência no tema de PRV, com quatorze (14) publicações e também apresentou menor destaque para o tema sobre QA, com seis (6) (Figura 2B).

A região Norte teve pouca participação nas produções e na diversidade dos temas. Foi encontrada uma (1) publicação, com ênfase para o tema da EA (Figura 2C).

Figura 2: Publicações científicas sobre proteção e recuperação de nascentes em área rural: 2A) Região Centro-Oeste; 2B) Região Nordeste; 2C) Região Norte 


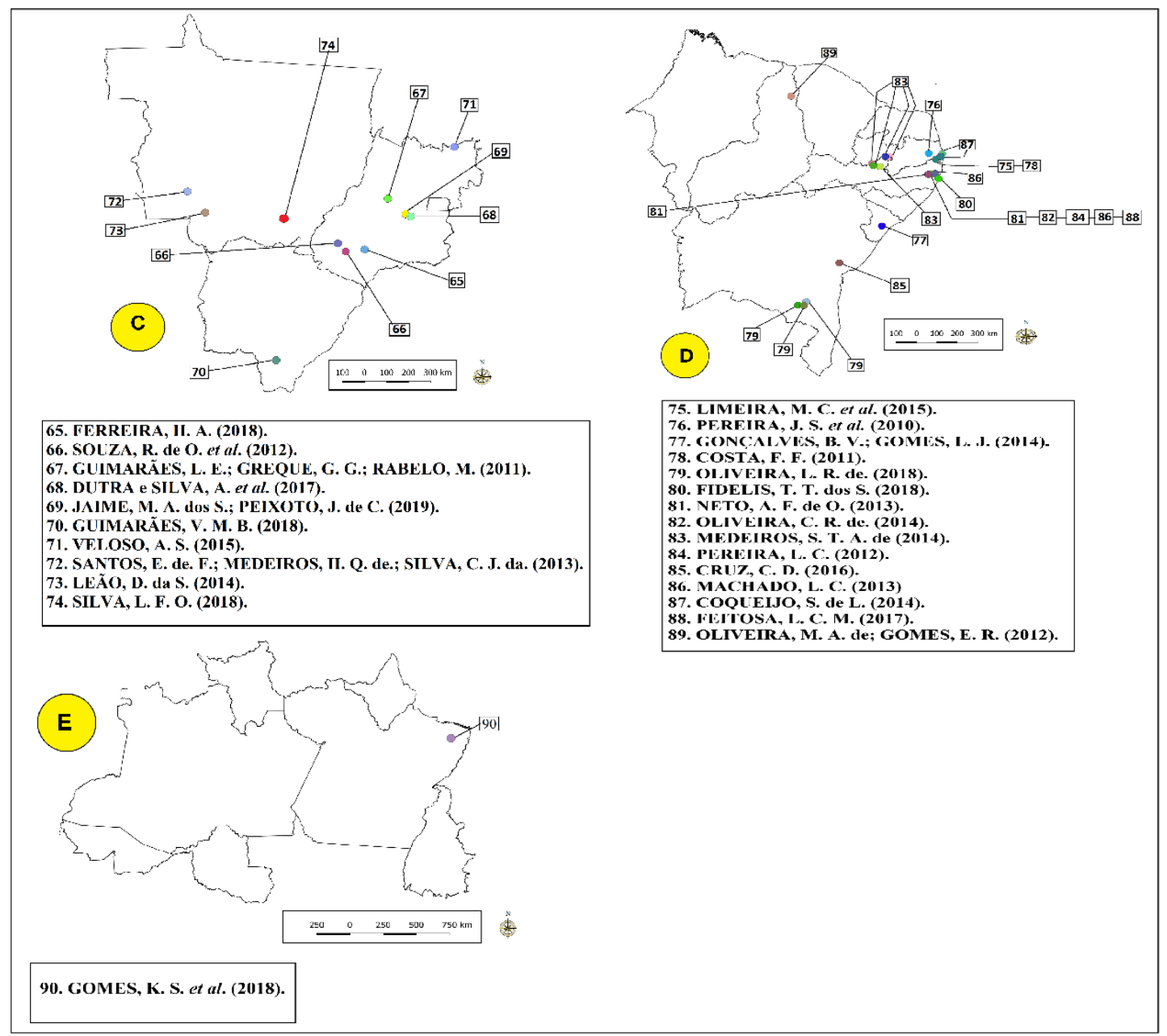

Fonte: Autores (2020).

Percebe-se uma discrepância regional na produção científica sobre a proteção e recuperação de nascentes em áreas rurais no Brasil (Figura 3). Sendo assim, faz-se necessário incentivar e fomentar a pesquisa principalmente nas regiões Norte, CentroOeste e Nordeste.

O tema de maior ocorrência foi sobre Preservação e Reflorestamento da Vegetação (PRV) com sessenta e três (63) publicações, seguido de Educação Ambiental (EA) com cinquenta e cinco (55), Técnicas implantadas ( $\mathrm{TI}$ ) com quarenta e três (43) e Monitoramento/Análise da qualidade da água (QA) com trinta (30).

O tema de PRV abordou sobre a situação da vegetação entorno das nascentes, do plantio e replantio de mudas para auxilio da proteção e recuperação de nascentes e também alinhado à construção de matérias juntamente com a pauta de EA que trata do tema da proteção da vegetação em áreas de nascentes.

Haas e Verdum (2009) propuseram avaliar um projeto organizado pela Prefeitura de Rolante/RS intitulado "Projeto de Recuperação e Proteção das Nascentes da Sub-Bacia do

ISSN: 2236-837X 
Rio Rolante-RS", compreendendo avaliar se o projeto levou em consideração os limites estipulados pelo Código Florestal na proteção de nascentes.

Villwock, Crispim e Rocha (2014) tiveram por objetivo, por meio do projeto "Mil Árvores", o replantio de nativas na bacia hidrográfica do rio do Campo em parceria com uma empresa local do município de Campo Mourão/PR.

\begin{abstract}
Nesta perspectiva de melhoria ambiental, a organização Cristófoli Biossegurança em conjunto com a Universidade Estadual do Paraná, campus de Campo Mourão implantou no ano de 2011 o projeto Mil Árvores em parceria com a Companhia de Saneamento do Estado do Paraná (SANEPAR), Prefeitura Municipal do município de Campo Mourão, Instituto Ambiental do Paraná (IAP), Fundação Educere, Companhia Paranaense de Eletricidade (COPEL) e Usicampo e vem realizando trabalhos socioambientais em escolas e comunidade rural da região (VILLWOCK, CRISPIM e ROCHA, 2014, p. 2).
\end{abstract}

Outro exemplo de trabalho selecionado foi desenvolvido por Barrichello, Pinheiro e Rorato (2015). Este trabalho em questão visou organizar uma trilha ecológica em área de nascente arranjado por meio da prática de EA com a escola do município de Dona Franscica/RS, explanando a importância a sensibilização ambiental com a temática do reflorestamento.

\begin{abstract}
Além das trilhas ecológicas, também foram realizados plantios de espécies florestais nativas ao longo do Rio Jacuí e alguns afluentes como o arroio Trombudo. As crianças e responsáveis foram convidados a fazer o plantio de mudas de espécies como louro-pardo, angico-vermelho, araçá, cerejeira, ingá, aroeira pimenteira, guajuvira, entre outras, em Área de Preservação Permanente como uma primeira iniciativa para a recuperação ambiental desses locais (BARRICHELLO, PINHEIRO e RORATO, 2015, p. 73).
\end{abstract}

A temática de EA tiveram em suas produções as ações de sensibilização ambiental para proteção de nascentes por meio da EA formal realizado dentro do ambiente educacional com a construção de materiais didáticos. Por intermédio de ações práticas nestas localidades, também foram selecionadas as produções de EA não formal, realizando a sensibilização ambiental para a proteção de nascentes por meio de palestras e entrevistas junto com moradores rurais.

Ferreira et al. (2016) visaram elaborar uma cartilha a partir de visitas em propriedades rurais. A cartilha procurou orientar melhorias para a realidade das áreas de nascentes encontradas.

A partir das respostas obtidas por meio dos questionários e dos dados coletados nas propriedades, foi possível elaborar uma cartilha direcionada aos proprietários quanto à importância da manutenção da recuperação das nascentes. Esta cartilha teve como objetivo também, instruir outras pessoas tais como estudantes e outros proprietários rurais a terem mais conhecimento sobre a recuperação de outras nascentes (FERREIRA et al, (2016), p. 96). 
Outro trabalho relacionado à EA diz respeito a questão do pagamento de parte do ICMS ecológico para agricultores rurais a fim de dar condições para que os mesmos possam preservar áreas de nascentes. Esta publicação foi desenvolvida no município de Apucarana/PR, que dispõe de uma legislação municipal e que tem realizado essas ações.

O número de nascentes cadastradas no Projeto até o final de 2010 somando-se a Bacia do Rio Pirapó e Rio Tibagi chega a 385 nascentes,em 133 propriedades recebendo uma contrapartida monetária como incentivo e auxílio à manutenção do custeio de preservação e manutenção das mesmas. O dinheiro repassado é parte integrante do ICMS Ecológico repassado ao município. $O$ aumento crescente do cadastro de novos proprietários rurais ao Projeto é um indicativo do sucesso desse plano de ação para preservação das áreas das nascentes (PINTO et al, 2011, p. 10).

As publicações referentes à TI visaram construir e avaliar mecanismos de proteção e recuperação de nascentes como as técnicas do Solo-Cimento e do modelo Caxambu e perpassam também o cercamento entorno da área da nascente para supressão de animais nestas localidades, ao qual podem agravar a poluição das águas consumidas, uma vez que esses animais podem gerar excreções nestas localidades.

Capelari (2016) objetivou analisar as condições das nascentes protegidas por meio do projeto “Água Limpa”, desenvolvido no município de Francisco Beltrão/PR.

Dentre avaliação, discutiu-se a presença de animais ao entorno das nascentes e o papel do cercamento para evitar esse problema. "Para avaliar o estado de conservação das nascentes de água, foram estabelecidos os seguintes parâmetros: presença de animais de criação, ocorrência de processos erosivos no solo, a existência de mata ciliar e proteção por cercas" (CAPELARI, 2016, p. 19).

Os objetivos analisados foram encontrados presentes nas proteções das nascentes por meio deste projeto, cumprindo o que foi proposto.

Carneiro et al. (2016) discorreram sobre avaliação de um sistema alternativo para o tratamento da água. O sistema em si desenvolvido foi o sistema Caxambu com adição de um filtro para remoção de materiais grosseiros,

O principal intuito desta etapa de tratamento foi remover sólidos grosseiros e alguns organismos e materiais finos, a fim de haver um amortecimento dos picos de turbidez em períodos de intensas chuvas. Nessa unidade, a finalidade é que o efluente seja filtrado de maneira ascendente e o afluente pré-filtrado seja encaminhado à unidade subsequente (CARNEIRO et al., 2016, p. 7).

O objetivo se completa com a avaliação físico-química da qualidade da água (QA), alinhando desenvolvimento da técnica e a inspeção da qualidade que esta técnica proporciona para melhoria da qualidade da água.

Mesmo o sistema sendo de fácil operação e de baixo custo, percebeu-se, através dos resultados de qualidade de água, que o mesmo é eficiente em relação a alguns parâmetros físico-químicos analisados, porém para o tratamento microbiológico efetivo, exigido pela Portaria 2.914/2011, o

ISSN: 2236-837X 
sistema necessita de um processo de desinfecção (CARNEIRO et al., 2016, p. 11).

A construção da técnica mais a coleta da água para averiguar a redução de poluentes e seu índice de potabilidade ajudará a compreender se a mesma está sendo eficiente e o que pode ser modificado em caso de resultados negativos.

Bermar et al. (2012) propuseram desenvolver a técnica do Solo-Cimento em quatro propriedades rurais no município de Assis Chateaubriand/PR. Foi descrito que a técnica trouxe melhorias referentes à queda de poluentes na água destas nascentes. "Com relação a eficiência do método na obtenção da qualidade da água, resultados preliminares mostraram a redução dos coliformes fecais e totais em uma das nascentes protegidas, sendo importante a realização das outras análises para afirmar tal resultado" (BERMAR et al., 2012, p. 3).

Apesar da eficiência descrita, os autores não apresentaram dados antes e posterior às nascentes protegidas.

A última temática das publicações referentes à QA discutiu sobre as análises físicoquímicas (microbiológica) das águas das nascentes, ao qual sempre esteve em consonância com a antiga Portaria 2.914/2011 do Ministério da Saúde que dispõe sobre índices ideais para consumir água de qualidade. A Portaria em si foi transformada em Portaria de Consolidação n 5 de 2017 do Ministério da Saúde.

Foram selecionadas as produções referentes à QA sobre as análises macroscópicas das nascentes. Tais análises visam identificar a qualidade das nascentes por meio da identificação visual do pesquisador.

Essa metodologia tem 0 intuito de analisar as condições ambientais e 0 grau de preservação dessas nascentes a partir de uma avaliação visual, sendo que cada nascente deve ser avaliada individualmente e o grau de proteção delas dependerá da quantidade de parâmetros macroscópicos definidos na pesquisa (RAMOS e SANTOS, 2018, p. 3).

Funguetto e Perondi (2015) visaram avaliar a qualidade da água das nascentes antes e após a proteção. A proteção foi realizada por meio do projeto "Água e Qualidade de Vida" no município de Itapejara d'Oeste".

Em relação à avaliação da qualidade da água, pode-se concluir que não se constataram mudanças significativas para os parâmetros $\mathrm{pH}$, dureza total, cloretos, ferro, cálcio, magnésio, turbidez e sólidos totais.

A alcalinidade total aumentou com a proteção da fonte, o que se pode explicar pelo fato das coletas das amostras (antes da proteção) terem sido realizadas após chuvas.

Os teores de cálcio aumentaram com a proteção das fontes, o que se explica pela adoção de cimento na proteção das fontes.

Constatou-se que havia apenas duas que realmente haviam sido protegidas conforme o projeto (proteção das fontes em solo-cimento). Aqui pode estar um dos motivos da não verificação de alterações significativas nos indicadores físico-químicos da água das fontes protegidas (FUNGUETTO e PERONDI, 2015, p. 15).

ISSN: 2236-837X 
Os dados negativos apresentados mostram a importância de quantificar a qualidade da água, pois, proporciona transparência sobre situação encontrada, visando modificar a técnica e os métodos de proteção para aquela localidade.

Villwock, Crispim e Cansian (2015) avaliaram a qualidade da água do ponto de vista microscópico antes e posterior à proteção de quatro nascentes, apresentando resultados positivos para os parâmetros selecionados.

Conforme as análises da situação da nascente antes e após a proteção, observamos que as nascentes apresentaram redução de contaminantes em pelo menos três dos quatro parâmetros, apresentando melhoria da qualidade da água, conforme os gráficos $1,2,3$ e 4 , nos quais se apresentam os resultados das análises da água, por isso é importante observar a queda nos parâmetros de análise (VIIWOCK, CRISPIM e CANSIAN, 2015, p. 149).

Os parâmetros selecionados foram: Bactérias Heterotróficas; Coliformes Totais; Coliformes Termotolerantes e Pseudomonas aeruginosa em quatro propriedades.

Os dados elevados para estes parâmetros podem gerar contaminações e risco para a saúde dos moradores que consomem esta água, daí a importância em mensurar estes níveis para testar a eficiência da proteção e recuperação das nascentes.

Dentre as publicações, os temas com mais destaques na região Sul são: EA com vinte e quatro (24) produções e o tema com menos destaque foi sobre QA com onze (11) (Tabela 1).

Na região Sudeste, os temas com maiores ocorrências são: PRV com dezenove (19) publicações. Já o tema menos enfatizado foi TI com dez (10) (Tabela 1).

Figura 3: Mapa de intensidade de produções científicas sobre proteção e recuperação de nascentes em áreas rurais por regiões brasileiras

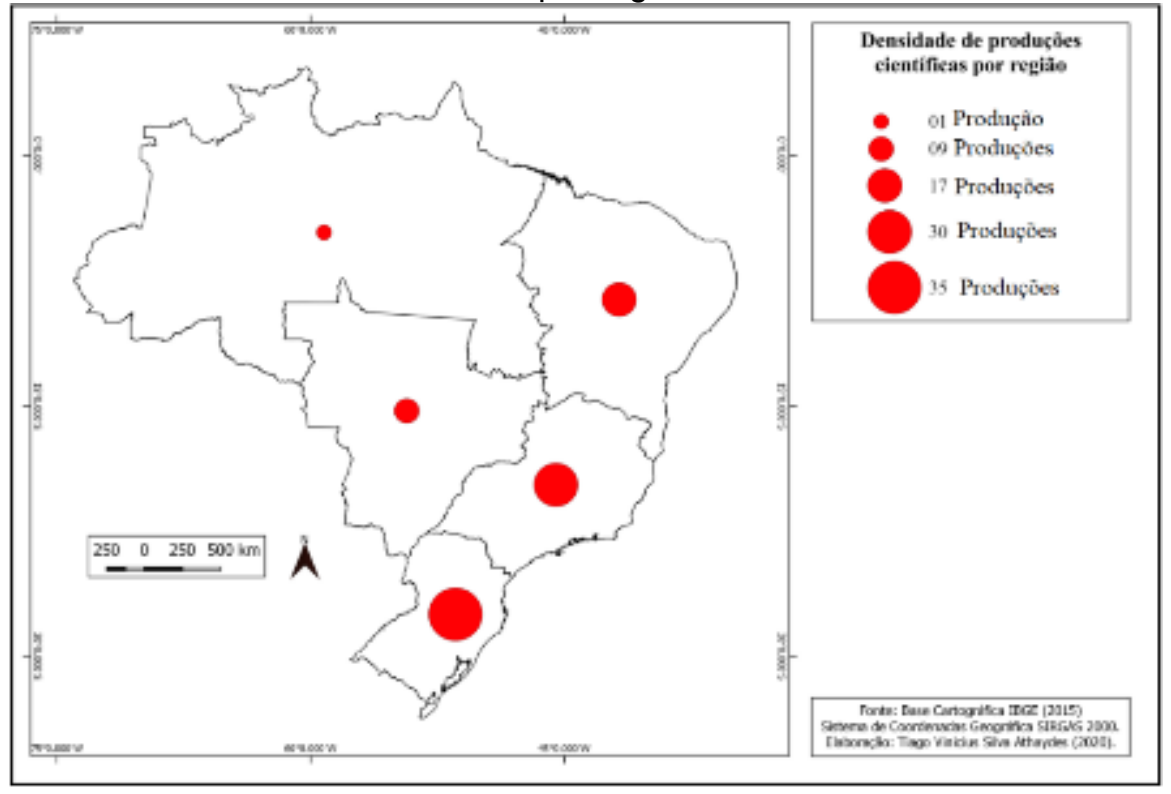

Fonte: Autores (2020).

ISSN: 2236-837X 
A ênfase em publicações sobre a PRV (70\%) tem pontos positivos no que tange à busca pela proteção florestal em áreas de nascentes, contribuindo para o cumprimento da Lei no 12.651/2012 do Código Florestal.

Faz-se importante a integração dos mecanismos de reflorestamento e preservação com o tema de $\mathrm{TI}$, que esteve presente em 47,7\% das publicações, como por exemplo, construindo a proteção por meio dos modelos de Solo-Cimento ou Caxambu no afloramento da nascente e também cercando no raio de cinquenta metros $(50 \mathrm{~m})$ da vegetação conforme o Código Florestal (12.651/2012), evitando o contato de animais com a água consumida. O contato de animais pode provocar contaminações da água por meio da defecação.

As publicações sobre QA ficaram abaixo dos demais temas (33,33\%). O número relativamente baixo com este tema pode ser preocupante, pois se faz necessário compreender se a qualidade da água está adequada para o consumo após as etapas de proteção e recuperação das nascentes. Desta forma, analisar a qualidade da água visa confirmar se as técnicas de proteção e recuperação de nascentes estão corretas ou se exigem novas medidas, a fim de garantir água potável.

No que tange às pesquisas de recuperação e proteção de nascentes, seria muito interessante que os temas PRV, TI e QA pudessem ser integrados.

As recomendações da integração destes critérios podem estar em materiais do tema da EA e.g. cartilhas técnicas, demonstrando o passo a passo para recuperar e proteger uma nascente, reuniões e apresentações audiovisuais com os agricultores, visando mostrar a importância destas práticas para suas vidas e para o seu meio de vivência. O tema EA esteve presente em $61,1 \%$ das produções.

Em relação às áreas de conhecimento, as que se sobressaíram foram Biologia, com vinte e oito (28) produções; Geografia, com vinte (20) e Agronomia com dezoito (18).

Os pesquisadores com maiores participações nas produções estão em conformidade com as áreas com maiores participações nas publicações. Os pesquisadores com maiores participações são: Quarenta e um (41) Biólogos; trinta e cinco (35) Geógrafos e vinte e cinco (25) Agrônomos.

GRÁFICO 1: Áreas do conhecimento e pesquisadores com maiores publicações sobre proteção e recuperação de nascente em áreas rurais

ISSN: 2236-837X 


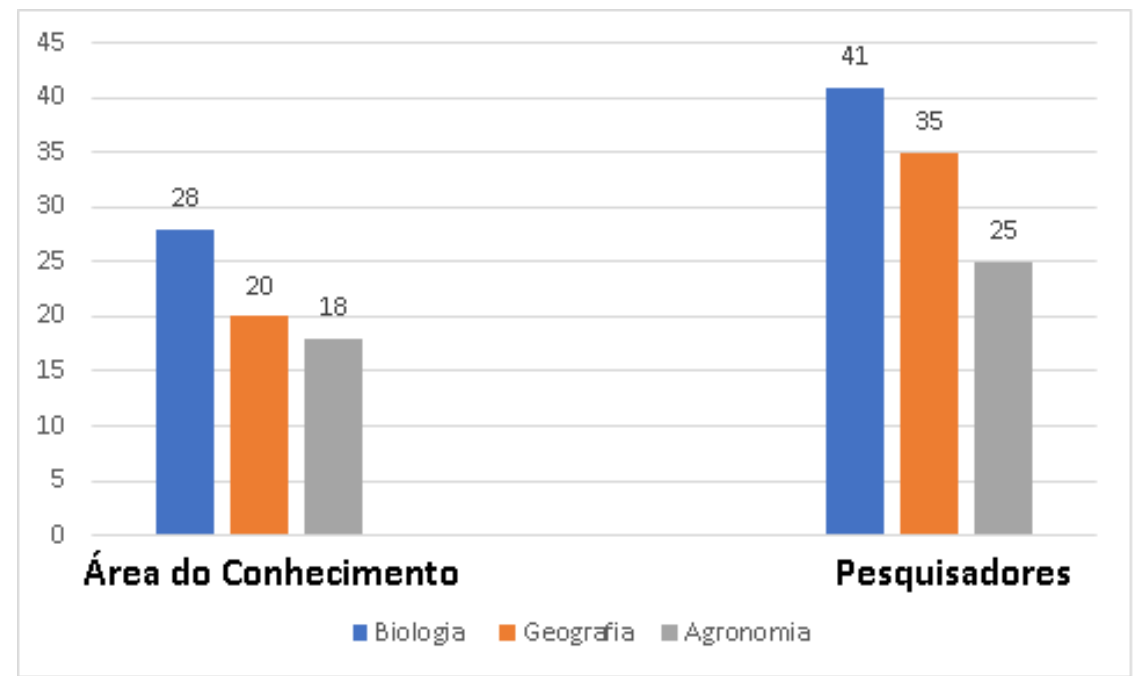

Fonte: Autores (2020).

Em síntese, o fortalecimento das publicações de proteção e recuperação de nascentes está mais estruturado nos cursos cuja formação aborda temas de cunho ambiental: Biologia e Geografia e de temas ligados ao espaço rural como o caso da Agronomia. Nas demais áreas, as publicações são esporádicas e a recuperação de nascente não se enquadra como o objetivo central dos estudos.

Entretanto, áreas como Eng. Sanitária, Tec. Ambiental e Eng. Agrícola-Ambiental, que tiveram baixa participação nas publicações, configuram-se áreas ligadas a assuntos ambientais e agrários.

As produções mostraram aumento do interesse em pesquisar sobre a temática da proteção e recuperação de nascente na área rural (Gráfico 2). A evolução das publicações não se deu de forma linear. As publicações encontradas se apresentaram entre 2003 a 2019.

GRÁFICO 2: Evolução temporal das produções sobre proteção e recuperação de nascentes na área rural

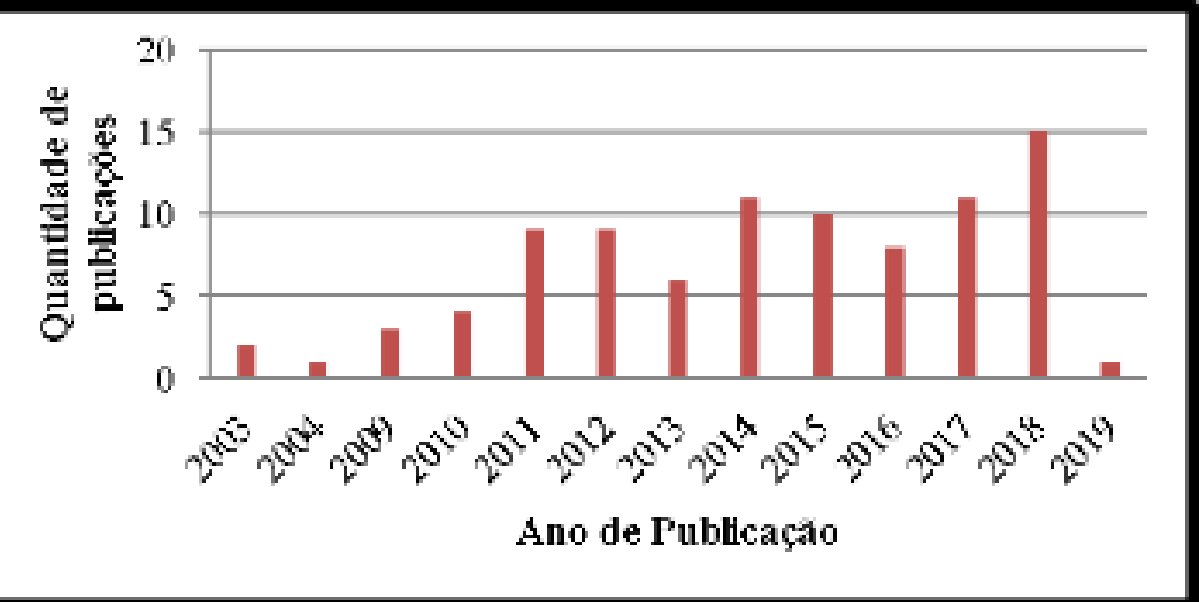

Fonte: Autor (2020).

ISSN: 2236-837X 
Os anos com maiores publicações foram: 2014 com onze (11); $2015 \mathrm{com}$ dez (10); 2017 com onze (11) e 2018 com quinze (15) produções.

A representação foi de $52,2 \%$ do total das produções. Apesar dos picos com menores publicações nos anos de 2004, 2013 e 2016, as publicações sobre proteção e recuperação de nascentes têm evoluído desde 2003 até 2018.

Em contrapartida, os anos com menores produções foram: 2003 com duas (2); 2004 com uma (1) e 2009 com três (3). A representação foi de 6,6\% do total das produções.

O ano de 2019 representou um déficit na evolução quando comparado entre 2003 a 2018, o que pode estar relacionado com as produções que ainda serão divulgadas em revistas científicas, anais de eventos e nas plataformas de dissertação e teses das Universidades Públicas e Privadas do país.

Desta forma, fortalecer as publicações científicas sobre este tema também está alicerçado no desenvolvimento de práticas para o saneamento básico rural, setor que teve pouco prestígio, reconhecido pelo Estado brasileiro por meio de seu Programa Saneamento Brasil Rural (PSBR), criado em 2019.

$\mathrm{Na}$ história do saneamento no Brasil, as demandas de áreas mais urbanizadas e economicamente viáveis sempre receberam maior atenção do poder público. Nas áreas rurais, as demandas têm sido preferidas no contexto local, havendo o predomínio de ações compartimentalizadas. Esta situação foi apontada pelo Plano Nacional de Saneamento Básico, o Plansab, em suas bases mais gerais, e por meio da indicação de um programa específico para áreas rurais, este Programa Saneamento Brasil Rural (PSBR, 2019, p. 2).

O déficit no setor rural pode estar ligado à concentração da população brasileira nas áreas urbanas, e desta forma, as práticas e políticas para o saneamento na área rural não se fortaleceram.

Outro ponto enfatizado refere-se à participação de pesquisadores de instituições públicas e privadas. Do total das publicações, setenta e oito (78) são pesquisadores filiados a instituições públicas e doze (12) são de pesquisadores filiados a instituições privadas (Gráfico 3).

GRÁFICO 3: Instituições públicas e privadas presentes em publicações sobre proteção e recuperação de nascentes na área rural 


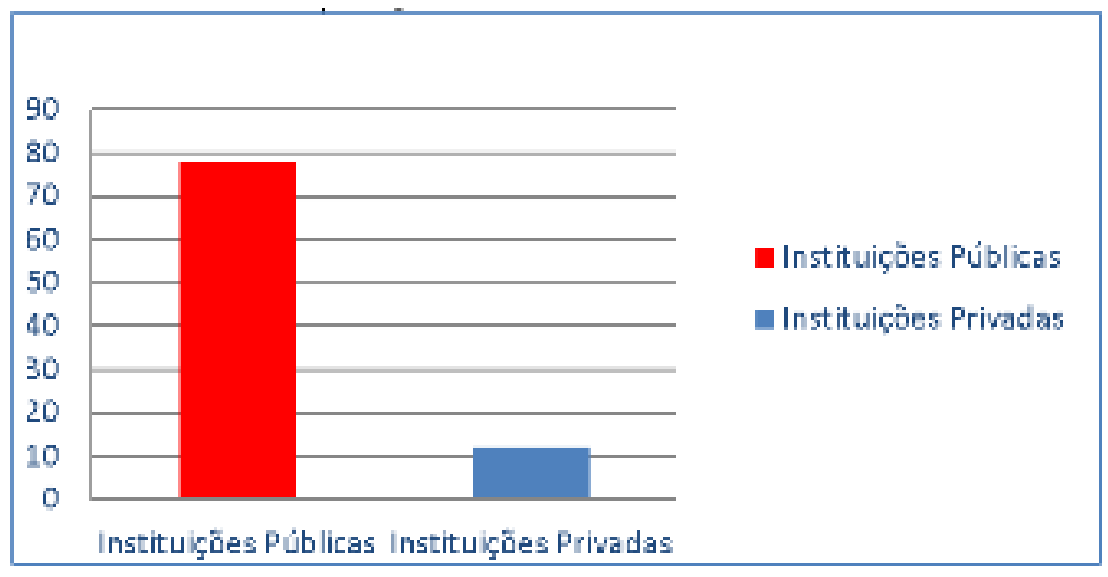

Fonte: Autor (2020).

Para a região Sul, tem-se o destaque nas publicações para Universidades Federais e Estaduais, como: Universidade Federal de Santa Maria (UFSM) e a Universidade Tecnológica Federal do Paraná (UTFPR) com cinco (5); Universidade Federal do Rio Grande do Sul (UFRGS), Universidade Estadual do Paraná (UNESPAR) e Universidade do Oeste do Paraná (UNIOESTE) com quatro (4).

Na região Sudeste, tem-se o destaque das publicações por parte das Universidades Federais, entre elas se destacam: a Universidade Federal do Espirito Santo (UFES) com três (3); Universidade Federal de Minas Gerais (UFMG), Universidade Federal de Lavras (UFLA), Instituto Federal do Sul de Minas (IFSULDEMINAS) e Universidade Federal de Itajubá (UNIFEI) com duas (2) publicações cada.

A região Centro-Oeste apresenta um diferencial das duas primeiras regiões apresentadas. Nesta, o destaque foi para a Universidade Privada e Universidade Federal, com duas (2) publicações organizadas pelo Centro Universitário de Anápolis (UniEVANGÉLICA) e pela Universidade Federal do Triângulo Mineiro (UFTM).

A região Nordeste tem o destaque de publicações por parte de Universidades Federais, com destaque para a Universidade Federal de Pernambuco com seis (6) e a Universidade Federal da Paraíba (UFPB) com (3).

Considerando as publicações desenvolvidas pelas regiões Sul, Sudeste e CentroOeste, a região Nordeste foi à única que não teve publicações geridas por instituições privadas. Tal fato pode estar ligado à concentração de Universidades Federais nesta região em detrimento das Universidades Privadas. A região Norte apresentou uma publicação, organizada por pesquisadores ligados à Universidade Federal Rural da Amazônia (UFRA).

A falta de publicações nesta região pode estar ligada ao baixo número de Universidades Públicas em relação às demais regiões brasileiras.

ISSN: 2236-837X 
A maior participação de pesquisadores vinculados às instituições públicas vai de encontro ao estipulado por Barros e Aultran (2019), que estudaram a colaboração científica e indexação na Web of Science nas universidades federais da Paraíba e Campina Grande.

No Brasil, especificamente, as universidades são as grandes produtoras de conhecimento, inovação e tecnologia, e parte desse conhecimento é indexado em bases de dados para que as comunidades científicas nacionais e internacionais conheçam 0 estado da arte da ciência desenvolvida no Brasil (BARROS e AUTRAN, 2019, p. 2).

Em números reais, Moura (2019) destaca que 95\% das produções brasileiras que estão em indexadores internacionais são de universidades públicas.

Essas produções são destaques graças ao financiamento público por meio de órgãos como a CAPES (Coordenação de Aperfeiçoamento de Pessoal de Nível Superior) que se encontra alocado no MEC (Ministério da Educação), do CNPq (Conselho Nacional de Desenvolvimento Científico e Tecnológico) que está posto no MCTIC (Ministério da Ciência, Tecnologia, Inovações e Comunicações) e de órgãos como a EMBRAPA e órgãos estaduais de Ciência e Tecnologia.

O fomento por parte destas instituições abarca as Universidades e Centro de Pesquisas públicas e instituições sem fins lucrativos. Portanto, a concentração de pesquisas por estas instituições se destacou mais que as instituições privadas.

O fortalecimento por parte das políticas públicas tem papel fundamental para aprimorar os cuidados para a proteção e recuperação de nascentes. Em destaque temos a criação da Lei Federal 14.119/2021 que institui o Pagamento por Serviços Ambientais e estimula os produtores de água.

\footnotetext{
Art. 4ํ Fica instituída a Política Nacional de Pagamento por Serviços Ambientais (PNPSA), cujos objetivos são:

$[\ldots]$

V - incentivar medidas para garantir a segurança hídrica em regiões submetidas a escassez de água para consumo humano e a processos de desertificação;

[...] (BRASIL, 2021).
}

A premiação realizada para aqueles que protegem as nascentes tem atraído outros produtores rurais. Esta questão pode ajudar a disseminar estas ações de proteção, favorecendo boas práticas em detrimento das práticas poluidoras.

\section{CONCLUSÃO}

O mapeamento sobre publicações científicas voltadas para a proteção e recuperação de nascentes no meio rural mostrou grande desigualdade regional ainda

ISSN: 2236-837X 
presente em nosso país, tendo concentrado mais publicações nas regiões Sul e Sudeste e menos na região Norte.

A discrepância entre a região Norte para as demais sobre este tema tem relação com o fato de a região ser a que menos tem práticas corretas de saneamento básico no Brasil. Exposto este fato, cumpre-se olhar por parte das instituições públicas (Governo Federal, Estadual, Municipal) e as agências de fomento públicas para esta localidade a fim de garantir um desenvolvimento equitativo com as demais regiões.

As publicações sobre as nascentes mostraram que este tema é um elemento complexo, precisando ser analisado de forma integrada, abordando os critérios da Educação Ambiental, Análise e Monitoramento da Qualidade da Água, de Tecnologias Implementadas e da Preservação e Recuperação da Vegetação de forma conjunta.

$\mathrm{O}$ avanço para melhorias na qualidade de vida no meio rural faz-se necessário com o apoio técnico de entidades públicas e seus pesquisadores, atrelado a ações de Educação Ambiental que visem à sensibilização, conscientização para realizar proteção das nascentes utilizadas por moradores do espaço rural, garantindo uma água de qualidade.

As abordagens da Educação Ambiental devem estar conectadas a todas as publicações de proteção e recuperação de nascentes na área rural, visando à sensibilização e a disseminação do conhecimento sobre a temática para os moradores. $O$ critério da Educação Ambiental esteve presente em 61\% das publicações, não estando presentes em todas as publicações.

O progresso do apoio técnico, operacional e educacional só será possível se o poder público cumprir as metas estipuladas nas principais políticas públicas, como as propostas para a universalização do saneamento básico descritas no PLANSAB e no Programa Saneamento Brasil Rural (PSBR), visando à universalização no ano de 2038 no espaço rural para todas as regiões brasileiras.

\section{AGRADECIMENTOS}

O primeiro autor agradece pela bolsa de pesquisa. O presente trabalho foi realizado com a Coordenação de Aperfeiçoamento de Pessoal de Nível Superior - Brasil (CAPES) Código de Financiamento 001.

\section{REFERÊNCIAS}

AGRIZZI, D V.; CECÍLIO, R. A.; ZANETTI, S. S.; GARCIA, G. de O.; AMARAL, A. A. do.; FIRMINO, E. F. A.; MENDES, N. G. de S. Qualidade da água de nascentes do Assentamento Paraíso. Revista Engenharia Sanitária e Ambiental, v. 23, p. 557-568. 2018.

ISSN: 2236-837X 
AGRIZZI, D. V. Índice de qualidade da água de nascentes no assentamento Paraíso, Alegre, ES. Dissertação de Mestrado em Ciências Florestais. Universidade Federal do Espírito Santo UFES, Jerônimo Monteiro, 2012.

ALMEIDA, R. G. de. Proteção de nascentes a partir do modelo Caxambu: Uma alternativa para as propriedades rurais do munícipio de Caçador SC. Monografia de Especialização em Gestão Ambiental em Municípios. Universidade Tecnológica Federal do Paraná - UTFPR - Campus Medianeira, Medianeira, 2014.

ANDRADE, M. A. A.; GIACOMELLI, A. F. Diagnóstico e plano de ação para a recuperação de nascentes do Rio Rancho Mundo Corbélia PR. Revista Brasileira de Energias Renováveis, v. 1, p. 90-108. 2011.

ARAÚJO, D. C. A.; LOUZADA, L. N.; BARONY, F. J. A. Caracterização da nascente localizada no município de Dom Cavati- MG com vistas ao abastecimento da comunidade. In: VIII Congresso Brasileiro de Gestão Ambiental., 2017, Campo Grande. Anais do Congresso Brasileiros de Gestão Ambiental. Campo Grande, 2017. p. 1-7.

BAGGIO, A. J.; CARPANEZZI, A. A.; FELIZARI, S. R.; FUFFATO, A. Recuperação de nascentes no município de Machadinho - RS, associada a ervais comerciais arborizados. In: VI Congreso Sudamericano de Yerba Mate e II Simpósio Internacional de Yerba Mate y Salud., 2014, Montevideo. Anais Memórias. Montivideo, 2014. p. 134-134.

BARBOSA, A. O. S. Recuperação e conservação de nascentes: Implementando ações práticas e de educação ambiental para agricultores da bacia do rio Turvo Sujo em Coimbra/MG. In: XIX Exposição de Experiências Municipais em Saneamento., 2015, Poços de Caldas. Anais $45^{\circ}$ Assembleia Nacional da Assamae. Poços de Caldas, 2015. p. 1-14.

BARICHELLO, D. E. Ações práticas e de Educação Ambiental visando a proteção de nascentes no município de Dona Francisca, RS. Monografia de Especialização em Educação Ambiental. Universidade Federal de Santa Maria - UFSM, Santa Maria, 2014.

BARICHELLO, D. E.; PINHEIRO, D. K.; RORATO, D. G. Ações Práticas e de Educação Ambiental visando Preservar Nascentes, Dona Francisca, RS. Revista Monografias Ambientais, v. 14, p. 6475. 2015.

BARROS, K. J. de L. da C.; AUTRAN, M. de M. M. (2018, outubro). Colaboração científica e indexação na Web of Sciece: Análise das Universidades Federais da Paraíba e de Campina Grande - 2008-2018. In: XX Encontro Nacional de Pesquisa em Ciência da Informação (ENANCIB)., 2018, Florianópolis. Anais do XXENANCIB, Florianópolis, 2018. p. 1-8.

BERMAR, A. N.; PEREIRA, E. P.; TEIXEIRA, L. A. dos S.; MARIUSSI, V.; PEREIRA, V. C. Proteção e recuperação de nascentes em pequenas propriedades rurais no município de Assis ChateaubriandPR. In: V Encontro Regional de Agroecologia., 2012, Medianeira. Anais do 1o Seminário de Extensão, Pesquisa e Inovação do IFPR, Medianeira, 2012. p. 1-4.

BERNARDI, F. H.; LOPES, C. L.; AMARAL, L.; FÜLBER, V. Propostas de adequação ambiental de propriedade rural. Revista Engenharia Ambiental (Online), v. 8, p. 183/3-195. 2011.

BRASIL. Lei no 14.119, de 13 de janeiro de 2021. Institui a Política Nacional de Pagamento por Serviços Ambientais; e altera as Leis $n^{\circ} 8.212$, de 24 de julho de 1991, 8.629, de 25 de fevereiro de 1993, e 6.015, de 31 de dezembro de 1973, para adequá-las à nova política. Brasília, 2021.

BRASIL. Programa Saneamento Brasil Rural (PSBR). Brasília: Ministério da Saúde. Brasília. 2019.

BÜNDCHEN, V. R. Implantação de um projeto de recuperação ambiental em propriedades rurais com áreas de proteção permanente uma complexa trajetória rumo à sustentabilidade. Dissertação de Mestrado em Desenvolvimento. Universidade Regional do Noroeste do Estado do Rio Grande do Sul - UNIJUÍ, ljuí, 2011.

ISSN: 2236-837X 
CALIXTO, J. S.; GALIZONI, F. M.; SANTOS, I. F. dos.; SANTOS, N. M.; RIBEIRO, E. M. Agricultores familiares e nascentes: construção de estratégias participativas de conservação no médio Jequitinhonha, MG. In: XLII Congresso da SOBER., 2004, Cuiabá. Anais XLII Congresso da Sociedade Brasileira de Economia e Sociologia Rural, Cuiabá, 2004. p. 1-13.

CAPELLARI, A. Proteção das nascentes: O projeto "Água e qualidade de vida" no município de Francisco Beltrão - PR. Dissertação de Mestrado em Desenvolvimento Rural Sustentável. Universidade Estadual do Oeste do Paraná - UNIOESTE - Campus de Marechal Cândido Rondon. Marechal Cândido Rondon. 2017.

CARNEIRO, C. G. Desenvolvimento e desempenho de sistemas alternativos de tratamento de água em localidades rurais da região Serrana de Santa Catarina. Dissertação de Mestrado em Engenharia Ambiental. Universidade Federal de Santa Catarina - UFSC, Florianópolis. 2017.

CARNEIRO, C. G.; SOUZA, F. H.; BUCK, A. L. B.; SARTORI, S.; SKORONSKI, E.; SENS, M. L. Desenvolvimento de um sistema alternativo para o tratamento de água oriunda de nascente em propriedades rurais. In: $27^{\circ}$ Congresso Nacional de Saneamento e Meio Ambiente e Feira Nacional de Saneamento e Meio Ambiente - Fenasan. 2016, São Paulo. Anais do 27ํ Congresso Nacional de Saneamento e Meio Ambiente e Feira Nacional de Saneamento e Meio Ambiente - Fenasan, São Paulo. 2016. p. 1-12.

COQUEIJO, S. de L. Relação sociedade - natureza: um estudo das nascentes nas comunidades rurais do Vale do Gramame - PB. Monografia de Geografia. Universidade Federal da Paraíba - UFPB. João Pessoa, 2014.

COSTA, F. F. A. Avaliação ambiental em áreas de nascentes na bacia hidrográfica do Alto Rio Gramame - PB. Dissertação de Mestrado em Engenharia Urbana e Ambiental. Universidade Federal da Paraíba - UFPB. João Pessoa, 2011.

CRISPIM, J. de Q.; MALYSZ, S. T.; PAROLIN, M.; JUNIOR, S. N. P. Implantação de tecnologias ambientais na casa familiar rural do município de Iretama - PR. Revista GeoNorte, v. 3, p. 208-220. 2012.

CRUZ, C. D.; NEVES, A. de J. das.; SAMPAIO, C. B. V.; POELKING, E. L. Nascentes hídricas do município de Cruz das Almas enfoque na zona rural. In: IV Congresso Baiano de Engenharia Sanitária e Ambiental. 2016, Cruz das Almas. Anais Congresso Baiano de Engenharia Sanitária e Ambiental. Cruz das Almas. 2016. p. 1-4.

DELEVATI, D. M.; KLEINERT, T. R.; TONIN, T. L. Projeto de Pagamento por Serviços Ambientais (PSA) na sub-bacia do Arroio Andréas - Bacia Hidrográfica do Rio Pardo - RS - Brasil. In: Congresso Regional de Iniciação Científica e Tecnológica em Engenharia. 2013, Passo Fundo. 2013, Passo Fundo. Anais do CRICTE - Congresso Regional de Iniciação Científica e Tecnológica em Engenharia 2013. Passo Fundo. 2013.

DUTRA e SILVA, A.; ALVARENGA, V. F. de A.; JUNIOR, T. J. de C.; OLIVEIRA, R. J. G. de; YOUSSEF, S. C. M.; BARBALHO, M. G. da S.; PEIXOTO, J. de C. Políticas de Conservação e Proteção Ambiental: Estudo de Caso das Nascentes do Ribeirão Piancó em Anápolis, Goiás. In: VIII SIMPÓSIO NACIONAL DE CIÊNCIA E MEIO AMBIENTE. 2017, Anápolis. Anais SNCMA, Anápolis, 2017. p. 1-10.

FARINHA, E. M. K.; MACHADO, L. R. de M. Educomunicação socioambiental para o programa revitalização de nascentes. Projeto apresentado à Associação Pró-Gestão das Águas da bacia hidrográfica do Rio Paraíba do Sul (AGEVAP), como requisito para participar da hierarquização de projetos de educação ambiental. Resende. 2016.

FEITOSA, L. C. M. Adequação metodológica para a avaliação do potencial de conservação de nascentes rurais. Tese de Doutorado em Desenvolvimento e Meio Ambiente. Universidade Federal de Pernambuco - UFPE. Recife, PE. 2017.

ISSN: 2236-837X 
FERNANDES, A. C. P. Projeto Água Viva - Monitoramento e recuperação de nascentes de abastecimento público no município de Bebedouro-SP. Trabalho de Conclusão de Curso de Especialização em Elaboração e Gerenciamento de Projetos para a Gestão Municipal de Recursos Hídricos. Instituto Federal de Educação, Ciência e Tecnologia do Ceará - IFCE. Fortaleza. 2018.

FERREIRA, C.; SOUZA, M. R. R. de.; SILVA, C. da.; ZAVARIZE, M.; BORBA, E. Análise socioambiental em propriedades rurais com nascentes em processo de recuperação no município de Lauro Muller (SC). Revista Ciência e Cidadania, v. 2, p. 92-102. 2016.

FERREIRA, H. A. Monitoramento da qualidade da água nos mananciais de abastecimento de Rio Verde - Goiás. Trabalho de Conclusão de Curso de Especialização em Elaboração e Gerenciamento de Projetos para a Gestão Municipal de Recursos Hídricos. Instituto Federal de Educação, Ciência e Tecnologia - IFCE. Fortaleza. 2018.

FIDELIS, T. T. dos S. Plano de ação ambiental para conservação de nascente da microbacia do riacho Algodoais - Cabo de Santo Agostinho - PE. Trabalho de Conclusão de Curso de Especialização em Elaboração e Gerenciamento de Projetos para a Gestão Municipal de Recursos Hídricos. Instituto Federal de Educação, Ciência e Tecnologia - IFCE. Fortaleza. 2018.

FOLLE, K. K.; PINHEIRO, D. K. Guardiões das Águas Mirins: Integrando experiências de preservação de recursos hídricos e educação ambiental no Município de Tenente Portela - RS. Revista Monografias Ambientais, v. esp, p. 26-44. 2015.

FUNGUETTO, R. F.; PERONDI, M. A. Avaliação de um projeto de recuperação das fontes d'água. In: 53ํㅡㄹ Congresso da Sociedade Brasileira de Economia, Administração e Sociologia Rural., 2015, João Pessoa. Anais 53 Congresso da SOBER. João Pessoa, 2015. p. 1-16.

GIACOMINI, I. F. Técnicas de restauração ecológica em nascentes e matas ciliares, Itaara, RS. Dissertação de Mestrado em Engenharia Florestal. Universidade Federal de Santa Maria - UFSM. Santa Maria. 2016.

GOMES, K. S.; OLIVEIRA, K. de N. S. de.; SOUZA, M. do S. P.; NETO, R. M. C. de F.; PENICHE, T. F. Educação Ambiental em Conjunto com Práticas de Recuperação de Nascente em uma Comunidade Rural de Irituia/PA. Cadernos de Agroecologia, v. 13, p. 20-25. 2018.

GOMES, R. T. D. Avaliação da técnica de proteção de nascentes com solo-cimento - Estudo de Caso na bacia hidrográfica do Rio Camboriú - SC. Dissertação de Mestrado em Ciência e Tecnologia Ambiental. Universidade do Vale do Itajaí - UNIVALI. Itajaí. 2019.

GOMES, S. D.; PORTO, E.; CONCEIÇÃO, R da. Recuperação de nascentes: Subsídios para a gestão de recursos hídricos no distrito de Santa Rita de Cássia, Barra Mansa - RJ. In: I Seminário Nacional de Meio Ambiente e Extensão Universitária., 2010, Marechal Cândido Rondon. Anais do I Seminário Nacional de Meio Ambiente e Extensão Universitária. Marechal Cândido Rondon, 2010. p. 1-4.

GONÇALVES, B. V.; GOMES, L. J. Percepção ambiental de produtores rurais na recuperação florestal da sub-bacia hidrográfica do rio Poxim - Sergipe. Revista Desenvolvimento e Meio Ambiente (UFPR), v. 29, p. 127-138. 2014.

GRITTEM, S.; TEIXEIRA, E. S. Diagnóstico ambiental participativo realizado com estudantes do ensino médio de uma escola do campo. In: XVI ENCONTRO PARANAENSE DE EDUCAÇÃO AMBIENTAL., 2017, Curitiba. Anais do XVI Encontro Paranaense de Educação Ambiental. Curitiba, 2017. p. 1-4.

GUIMARÃES, L. E.; GREBE, G. G.; RABALO, M. O uso de ferramentas participativas para o diagnóstico e sensibilização ambiental no projeto renascer em Itapuranga - Goiás. In: II Simpósio sobre Educação Ambiental e transdisciplinaridade., 2011, Goiânia. Anais do II Simpósio sobre Educação Ambiental e transdisciplinaridade. Goiânia, 2011. p. 1-12.

ISSN: 2236-837X 
GUIMARÃES, V. M. B. A escola e o renascimento da terra: educação na terra indígena Te'ýkue. Revista Pesquisa em Educação Ambiental (Online), v. 13, p. 82-100. 2018.

HAAS, M. B. Definição de parâmetros para a proteção de nascentes em propriedades rurais município de Rolantes/RS. Dissertação de Mestrado em Geografia. Universidade Federal do Rio Grande do Sul - UFRGS. Porto Alegre. 2010.

HAAS, M. B.; VERDUM, R. Definição de parâmetros para a proteção de nascentes. In: $12^{\circ}$ Encontro de Geógrafos da América Latina., 2009, Montevidéu. Anais do 12 Encontro de Geógrafos da América Latina. Montevideo, 2009. p. 1-6.

HANCKE, A. Projeto plantando vida: uma experiência do ensino de proteção de nascentes com a utilização de Solo-Cimento. In: $9^{\circ}$ Fórum Internacional de Resíduos Sólidos., 2018, Porto Alegre. Anais do: $9^{\circ}$ Fórum Internacional de Resíduos Sólidos. Porto Alegre, 2018. p. 1-5.

IAGLA, N. de M. Preservação e recuperação de nascentes. Trabalho de Conclusão de Curso de Especialização em Educação do Campo. Universidade Federal do Paraná - UFPR - Setor Litoral. Matinhos. 2011.

ISAIAS, R. M. dos S.; NORGUEIRA, M. M.; MOREIRA, A. S. F. P. Indicação de plantas úteis para a recuperação das nascentes de Milho Verde/Serro - MG. In: 6 Encontro de Extensão da UFMG., 2003, Belo Horizonte. Anais do 6o Encontro de Extensão da UFMG. Belo Horizonte, 2003. p.186191.

JAIME, M. A. dos S.; PEIXOTO, J. de C. Estudo de caso: Recuperação da principal nascente do Ribeirão João Leite, na sub-bacia do córrego das pedras, em Ouro Verde de Goiás, GO. In: 3o Congresso Internacional de Pesquisa, Ensino e Extensão., 2019, Anápolis. Anais do 3 Congresso Internacional de Pesquisa, Ensino e Extensão. Anápolis, 2019. p. 2883-2893.

JARDIM, P. B. Qualidade de água de nascentes como reflexo do manejo do uso e ocupação do solo e conservação da mata ciliar, no município de Ouro Branco - MG. Dissertação de Mestrado em Engenharia Ambiental. Universidade Federal de Ouro Preto - UFOP. 2010.

KIRST, A.; MALACARNE, V. O Ensino de Ciências na preservação da água em propriedades rurais: escola e família planejando um futuro melhor. In: Ângela Maria Piovezan Batista; Jane Célia Volpato; Maria Regina Bach. (Org.). O professor PDE e os desafios da escola pública paranaense 2012. 01ed, v. 01, p. 47-59. Curitiba/PR. 2014.

LEÃO, D. da S. O programa de educação ambiental e agricultura familiar (PEAAF) no assentamento Laranjeiras I, em região de nascentes do Pantanal - Cáceres - MT. Dissertação de Mestrado em Ciências Ambientais. Universidade Federal do Mato Grosso - UFMT. Cáceres. 2014.

LIMEIRA, M. C. M.; PINHEIRO, N. V.; SILVA, T. C. da.; FILGUEIRA, H. J. A.; BARBOSA, J. M. Métodos de Pagamento por serviços ecossistêmicos: aplicações em área de nascentes na bacia do rio Gramame, PB. Revista Gaia Scientia, v. 9, p. 156-163. 2015.

MACHADO, L. C. O papel das nascentes na sustentabilidade de assentamento rurais. Dissertação de Mestrado em Desenvolvimento e Meio Ambiente. Universidade Federal de Pernambuco - UFPE. Recife. 2013.

MARCIANO, A. G. Diagnóstico das nascentes da bacia hidrográfica do córrego do Vargeado Santa Rita do Sapucaí/MG. Comitê da Bacia Hidrográfica do Rio Sapucaí. Universidade Federal de Itajubá. Santa Rita do Sapucaí, MG. 2016.

MEDEIROS, S. T. A. de. Agroecologia com o potencial para recuperação de áreas degradadas em comunidades rurais de nascentes do rio Pajeú. Dissertação de Mestrado em Desenvolvimento e Meio Ambiente. Universidade Federal de Pernambuco - UFPE. Recife. 2014. 
MELO, H. S.; NASCIMENTO, V. A. do.; SILVA, T. C. de O. P. da.; NOGUEIRA, G. H. Educação Ambiental em uma Comunidade Rural: uma abordagem sobre a preservação de nascentes e matas ciliares. Revista Educação Ambiental, v. 1, p. 17-31. 2011.

MORAES, M. de F. M. Participação, integração e visibilidade: Agriculturas familiares no processo de produtivo e na sociedade - Um estudo de caso. Monografia de Especialização em Educação Ambiental. Universidade Cândido Mendes - UCAM. Volta Redonda. 2010.

MOURA, M. D. Universidades públicas respondem por mais de $95 \%$ da produção científica do Brasil. 2019. Ciência na rua. Disponível em: http://ciencianarua.net/universidadespublicasrespondem-por-mais-de-95-da-producao-cientifica-do-brasil/. Acesso em 15 janeiro de 2020.

NETO, A. F. de O. O papel das Nascentes no Abastecimento de Populações Rurais Difusas na Mata Pernambucana. Dissertação de Mestrado em Desenvolvimento e Meio Ambiente. Universidade Federal de Pernambuco - UFPE. Recife. 2013.

NOTZOLD, A. C. Agricultura e a preservação ambiental: 0 caso das nascentes do rio Erval Novo, Bom Progresso - RS. Monografia em Tecnologia em Planejamento e Gestão para o Desenvolvimento Rural. Universidade Federal do Rio Grande do Sul - UFRGS. Porto Alegre. 2011.

OLIVEIRA, C. R. de. Qualidade da água e conservação de nascentes em assentamento rural na Mata Pernambucana. Dissertação de Mestrado em Engenharia Civil. Universidade Federal de Pernambuco - UFPE. Recife. 2014.

OLIVEIRA, F. R. de. Qualidade hidroambiental de nascentes no assentamento Florestan Fernandes, sul do Espírito Santo. Dissertação de Mestrado em Ciências Florestais. Universidade Federal do Espírito Santo - UFES. Jerônimo Monteiro. 2018.

OLIVEIRA, G. A.; G. de A.; MORAIS, A. de A.; PIO, F. P. B.; SILVA, J. J. R. Aplicação da técnica de recuperação de nascentes em uma propriedade rural localizada no município de Itabira/MG. In: Congresso ABES/Fenasan., 2017, São Paulo. Anais Eletrônico ABES. São Paulo, 2017. p. 1-6.

OLIVEIRA, G. L.; ROCHA, R. E.; LIMA, S. M. B.; DUARTE, E. M. G. Uma Abordagem Agroecológica para Recuperação e Produção em Área Degradada. Revista Cadernos Agroecológicos, v. 13, p. 1. 2018.

OLIVEIRA, L. R. de. Caracterização das nascentes da sub-bacia hidrográfica do rio Gaviãozinho, Bahia. Dissertação de Mestrado em Agricultura Orgânica. Universidade Federal Rural do Rio de Janeiro - UFRRJ. Seropédica. 2018.

OLIVEIRA, M. A. de. Diagnóstico ambiental das nascentes do rio Parafuso, em Pedro II, Piauí. In: III Congresso Brasileiro da Gestão Ambiental., 2012, Goiânia. Anais do III Congresso Brasileiro da Gestão Ambiental. Goiânia, 2012. p. 1-17.

PARANHOS, F. R. da S. Proposta de recuperação e manejo de nascentes em área rural do município de Álvares Machado - SP. Trabalho de Conclusão de Curso em Engenharia Ambiental. Universidade Estadual Paulista Júlio de Mesquita Filho - UNESP. Presidente Prudente. 2012.

PASSOS, M. D. SANTOS, E. F.; DIAS, F. D. B.; LOPES, F. F.; MENDES, S. de C.; SANTOS, C. S.; RITA, F. S.; MORAIS, M. A. de. Qualidade físico-química da água de algumas nascentes de Muzambinho - Minas Gerais. In: XI Congresso Nacional de Meio Ambiente de Poços de Caldas., 2014, Poços de Caldas. Anais do XI Congresso Nacional de Meio Ambiente de Poços de Caldas. Poços de Caldas, 2014. p. 1-7.

PEREIRA, J. S.; SANTOS, R. T. dos.; FERREIRA, C. M. A.; JUNIOR, G. B.; OLIVEIRA, F. G. de. Recuperação e manejo da nascente "Chorona" na comunidade rural de Uruçu. Revista Extensão em Foco, v. 6, p. 81-89. 2010.

PEREIRA, L. C. Uso e conservação de nascentes em assentamentos rurais. Dissertação de Mestrado em Engenharia Civil. Universidade Federal de Pernambuco - UFPE, Recife, 2012. 
PINTO, L. V. A.; ROMA, T. N.; BALIEIRO, K. R. C. Avaliação qualitativa da água de nascentes com diferentes usos do solo em seu entorno. Revista CERNE (UFLA), v. 18, p. 495-505. 2012.

PINTO, V. P. S.; PINTO, J. de S.; SANTOS, C. A. dos.; FERNANDES, C. C.; ARAUJO, N. M. de. ICMS Ecológico: uma importante ferramenta incentivadora na criação e gestão de políticas públicas de preservação de nascentes. In: XVIII CONGRESSO BRASILEIRO DE CUSTOS., 2011, Rio de Janeiro. Anais do XVIII CONGRESSO BRASILEIRO DE CUSTOS. Rio de Janeiro, 2011. p. 1-11.

RAMOS, H. F.; SANTOS, D. C. R. M. O índice de impacto ambiental de nascentes (IIAN) e o grau de preservação das nascentes em propriedades rurais de Barra Mansa. In: III Simpósio de Recursos Hídricos da Bacia do Rio Paraíba do Sul., 2018, Juiz de Fora. Anais do III Simpósio de Recursos Hídricos da Bacia do Rio Paraíba do Sul. Juiz de Fora, 2018. p. 1-9.

RAMOS, H. F.; SANTOS, D. da C. R. M. dos.; PAIVA, R. F. da P. de S.; FREITAS, W. K. de. A

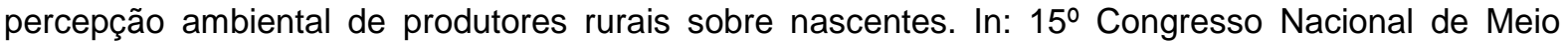
Ambiente., 2018, Poços de Caldas. Anais do 15o Congresso Nacional de Meio Ambiente. Poços de Caldas, 2018. p. 1-5.

RAMOS, M. M. Avaliação da implantação de técnicas de conservação e recuperação de nascentes e áreas degradadas: Estudo de Caso na comunidade rural de Padre Trindade, município de Formiga - MG. Trabalho de Conclusão de Curso em Engenharia Ambiental e Sanitária. Centro Universitário de Formiga - UNIFOR, Formiga, 2017.

RANGEL, A. R. M.; OLIVEIRA, V. P. S. de.; MOREIRA, M. A. C. O Programa Rio Rural no estado do Rio de Janeiro: A experiência na microbacia Canal Jurumirim, município de Macaé. Revista Monografias Ambientais (REMOA/UFSM), v. 15, p. 302-322. 2016.

RIBEIRO, E. M.; GALIZONI, F. M. Água, população rural e políticas de gestão: o caso do vale do Jequitinhonha, Minas Gerais. Revista Ambiente e Sociedade, v. V e VI, n.1 e 2, p. 129-146. 2003.

SANTOS, A. A. G. R.; SILVESTRE, L. H. A.; GALIZONI, F. M. Gestão das águas no Vale do Jequitinhonha: soberania alimentar. In: Seminário Visões do Vale 4. 2009, Belo Horizonte. Anais do Seminário Visões do Vale 4. Belo Horizonte, 2009. p. 1-8.

SANTOS, E. de L. F.; MEDEIROS, H. Q. de.; SILVA, C. J. da. Educação ambiental e diálogo de saberes em região de nascentes do Pantanal: Reserva do Cabaçal, Mato Grosso, Brasil. Revista Ciência \& Educação, v. 19, p. 879-896. 2013.

SANTOS, E. P. P.; VEIGA, W. A.; GONÇALVES, M. R. S.; THOMÉ, M. P. M. Coliformes Totais e Termotolerantes em água de nascentes utilizadas para o consumo humano na zona rural do município de Varre-Sai, RJ. Revista Scientia Plena, v. 11, p. 1-6. 2015.

SHIMITZ, L. A. Proteção de fontes de água em Unidades de Produção e Vida Familiares (UPVFS) no sudoeste do Paraná: Uma análise das ações desenvolvidas pela ACESI/STR, Geterr/Unioeste e Emater-PR. Dissertação de Mestrado em Geografia. Universidade Estadual do Oeste do Paraná - UNIOESTE - Campus de Francisco Beltrão, Francisco Beltrão, 2017.

SILVA, L. F. O. Métodos alternativos para a recuperação de nascente em uma propriedade rural no assentamento Padre Josimo Tavarez em São José do Povo - MT. Monografia de Engenharia Agrícola e Ambiental. Universidade Federal do Mato Grosso - UFMT, Rondonópolis, 2018.

SILVA, L. H. G. da. (2014). O ensino de ciências na escola do campo: Uma sustentabilidade na recuperação de nascentes. Trabalho de Conclusão de Curso de Especialização em Educação do Campo. Universidade Federal do Paraná - UFPR - Setor Litoral, Matinhos, 2014.

SILVA, T. S.; OLIVEIRA, T.; JUNQUEIRA, M. B. B. Água: A experiência dos programas de Educação Ambiental promovidos pelo Departamento Municipal de Água e Esgoto (DMAE) no Município de Uberlândia. Revista Eletrônica Do Mestrado em Educação Ambiental, v. 1, p. 253-266. 2018. 
SOUZA, I.; MARCON, G. Sistemas de proteção de fontes de água superficial e captação de água da chuva em propriedades rurais da microbacia do rio do Peixe. Revista Maiêutica - Tecnologia e Meio Ambiente, v.1, 21-28. 2014.

SOUZA, R. de O.; OLIVEIRA, R. M de.; LIMA, J. R. de S.; BENINCÁ, M. de C.; JUNIOR, V. S. Q. Recuperação de nascentes em áreas de projetos de assentamento no sudoeste de Goiás. In: V Simpósio sobre Reforma Agrária e Questões Rurais. 2012, Araraquara. Anais do VIII Simpósio Sobre Reforma Agrária e Questões Rurais. Araraquara, 2012. p. 1-8.

STOLF, D. F.; MOLZ, S. Avaliação microbiológica da água utilizada para consumo humano em uma propriedade rural de Taió - SC. Saúde e Meio Ambiente - Revista Interdisciplinar, v. 6, p. 96. 2017.

TERRA, R. A. F. Projeto adote uma nascente. Educação Ambiental e o processo de recuperação de uma área de preservação permanente. Monografia de Especialização em Ensino de Ciências. Universidade Tecnológica Federal do Paraná - UTFPR- Campus de Medianeira, Medianeira, 2013.

TONIAL, R. Levantamento e análise para a recuperação das nascentes e mata ciliar que compõem o rio Pato Branco. Trabalho de Conclusão de Curso em Agronomia. Universidade Tecnológica Federal do Paraná - UTFPR - Campus de Pato Branco, Pato Branco, 2015.

VELOSO, A. S. Implantação do sistema agroflorestal sucessional para a conservação de sete nascentes em área degradada por pastagem. Revisto Terceiro Incluído, v.5, n.2, p.428-451. 2015.

VILLWOCK, F. H.; CIBOTO, D. E.; CRISPIM, J. de Q. WILLWOCK, R. Recuperação e proteção de nascentes: o caso da comunidade Palmital 43, município de Mato Rico - PR. Revista Geofronter, v. 4, p. 124-139. 2018.

VILLWOCK, F. H.; CRISPIM, J. de Q.; ROCHA, J. A. da. Projeto socioambiental mil árvores. In: IX Encontro de Produção Científica e Tecnológica - EPCT. 2014, Campo Mourão. Anais IX Encontro de Produção Científica e Tecnológica - EPCT, Campo Mourão, 2014. p. 1-10.

VILLWOCK, F. H.; CRISPIM J. de Q.; CANSIAN, D. C. V. A. Melhoria da qualidade da água por meio da técnica de recuperação e proteção de nascentes em pequenas propriedades agrícolas no município de Campina da Lagoa - PR. Revista Meio Ambiente e Sustentabilidade, v. 9, p. 141-154. 2015.

WERLE, W. Pagamento por prestação de serviços ambientais um estudo do programa municipal de recuperação de nascentes de Três Passos/RS. Trabalho de Conclusão de Curso em Tecnologia em Desenvolvimento Rural. Universidade Federal do Rio Grande do Sul - UFRGS, Três Passos, 2013.

ZANZARINI, R. M. Mata ciliar e nascente no cerrado brasileiro - análise e recuperação ambiental. In: $12^{\circ}$ Encuentro de geógrafos de América Latina. 2012, Montevideo. Anais do $\mathbf{1 2}^{\circ}$ Encuentro de geógrafos de América Latina. Montevideo. 2012. p. 1-14 